\title{
Decompression surgery for spinal metastases: a systematic review
}

\author{
Dara Bakar, BA, ${ }^{6}$ Joseph E. Tanenbaum, BA, ${ }^{1,4,5}$ Kevin Phan, BS, $, 7,8$ Vincent J. Alentado, MD,,1,4 \\ Michael P. Steinmetz, MD, ${ }^{1,2}$ Edward C. Benzel, MD, ${ }^{1,2}$ and Thomas E. Mroz, MD ${ }^{1-3}$ \\ ${ }^{1}$ Center for Spine Health, and Departments of ${ }^{2}$ Neurosurgery and ${ }^{3}$ Orthopaedic Surgery, Cleveland Clinic; ${ }^{4}$ Case Western \\ Reserve University School of Medicine; ${ }^{5}$ Department of Epidemiology and Biostatistics, Case Western Reserve University, \\ Cleveland, Ohio; ${ }^{6}$ The Warren Alpert Medical School of Brown University, Providence, Rhode Island; ${ }^{7}$ NeuroSpine Surgery \\ Research Group, Prince of Wales Private Hospital, Sydney, Australia; and ${ }^{8}$ University of New South Wales, Sydney, Australia
}

OBJECTIVE The aim of this study was to systematically review the literature on reported outcomes following decompression surgery for spinal metastases.

METHODS The authors conducted MEDLINE, Scopus, and Web of Science database searches for studies reporting clinical outcomes and complications associated with decompression surgery for metastatic spinal tumors. Both retrospective and prospective studies were included. After meeting inclusion criteria, articles were categorized based on the following reported outcomes: survival, ambulation, surgical technique, neurological function, primary tumor histology, and miscellaneous outcomes.

RESULTS Of the 4148 articles retrieved from databases, 36 met inclusion criteria. Of those included, 8 were prospective studies and 28 were retrospective studies. The year of publication ranged from 1992 to 2015 . Study size ranged from 21 to 711 patients. Three studies found that good preoperative Karnofsky Performance Status (KPS $\geq 80 \%$ ) was a significant predictor of survival. No study reported a significant effect of time-to-surgery following the onset of spinal cord compression symptoms on survival. Three studies reported improvement in neurological function following surgery. The most commonly cited complication was wound infection or dehiscence (22 studies). Eight studies reported that preoperative ambulatory or preoperative motor status was a significant predictor of postoperative ambulatory status. A wide variety of surgical techniques were reported: posterior decompression and stabilization, posterior decompression without stabilization, and posterior decompression with total or subtotal tumor resection. Although a wide range of functional scales were used to assess neurological outcomes, four studies used the American Spinal Injury Association (ASIA) Impairment Scale to assess neurological function. Four studies reported the effects of radiation therapy and local disease control for spinal metastases. Two studies reported that the type of treatment was not significantly associated with the rate of local control. The most commonly reported primary tumor types included lung cancer, prostate cancer, breast cancer, renal cancer, and gastrointestinal cancer.

CONCLUSIONS This study reports a systematic review of the literature on decompression surgery for spinal metastases. The results of this study can help educate surgeons on the previously published predictors of outcomes following decompression surgery for metastatic spinal disease. However, the authors also identify significant gaps in the literature and the need for future studies investigating the optimal practice with regard to decompression surgery for spinal metastases.

http://thejns.org/doi/abs/10.3171/2016.6.FOCUS16166

KEY WORDS spinal metastases; decompression; spinal cord compression; survival; ambulation

$\mathrm{T}$ HE spine is the most common site of bony metastases, with $50 \%$ of all skeletal metastases occurring in the spine ${ }^{9,14}$ Among patients whose cause of death is malignant neoplasm, an estimated $30.6 \%$ have spinal metastases based on microscopic examination. ${ }^{27}$ Certain primary tumors, such as lung, breast, and prostate, have a higher frequency of metastases to the spinal column. ${ }^{44}$

Spinal cord compression is a common complication among patients with spinal metastases. Metastatic epidural spinal cord compression (MESCC) has been reported in

ABBREVIATIONS ASIA = American Spinal Injury Association; ECOG = Eastern Cooperative Oncology Group; EORTC $=$ European Organisation for Research and Treatment of Cancer; EORTC QLQ-BM22 = EORTC Bone Metastases module; EORTC QLQ-30 = Quality of Life questionnaire; KPS = Karnofsky Performance Status; MESCC = metastatic epidural spinal cord compression; PRISMA = Preferred Reporting Items for Systematic Reviews and Meta-Analyses; PSA = prostate-specific antigen; RR = risk ratio SUBMITTED April 1, 2016. ACCEPTED June 6, 2016. INCLUDE WHEN CITING DOI: 10.3171/2016.6.FOCUS16166. 
$5 \%-10 \%$ of all cancer patients. ${ }^{26}$ Spinal cord compression can cause disability and significantly impair quality of life. ${ }^{42}$ Although some patients with spinal metastases can be treated nonoperatively, patients who present with spinal cord compression often require surgical intervention to preserve neurological function. ${ }^{14}$

Decompression surgery is the standard surgical technique used to treat metastatic disease of the thoracic and lumbar spine. ${ }^{10}$ Location of metastatic disease determines the approach for decompression surgery. A ventral or dorsal approach, or both, can be used in the cervical, thoracic, and lumbar spine, depending on several factors. These include location of compression, goals of reconstruction if necessary, type of tumor, surgeon expertise, and patientspecific factors (e.g. comorbidities of body habitus). ${ }^{8}$

Although outcomes following decompression surgery have been reported in the literature for 5 decades, a systematic review of predictors of outcome following decompression surgery for spinal metastases has not been performed. The present study systematically reviews the current literature and examines reported outcomes following decompression surgery for spinal metastases. Specifically, we highlight predictors of survival and predictors of ambulation, as well as surgical techniques, neurological function outcomes, primary tumor histology outcomes, and miscellaneous outcomes.

\section{Methods \\ Study Search}

A systematic review was conducted in accordance with the guidelines of the Preferred Reporting Items for Systematic Reviews and Meta-Analyses (PRISMA). We conducted database searches of MEDLINE, Scopus, and Web of Science using the following search algorithm: (decompr* OR separat*) AND (spine or spina*) AND metasta* AND (surge* OR surgi*). This search returned 4148 citations (Fig. 1). The search period ended on January 22, 2016.

\section{Inclusion and Exclusion Criteria}

Clinical studies reporting outcomes of decompression surgery for spinal metastases were included within the study. Animal, in vitro, biomechanical, non-English language studies, book chapters, and case reports (defined as $\mathrm{n}<10$ ) were excluded. Due to the limited amount of data available, both retrospective and prospective studies were included.

\section{Data Collection}

Two reviewers (D.B. and K.P.) independently evaluated the initial 4148 retrieved citations. After removing 1914 duplicates, the titles and abstracts of 2234 publications were screened. ${ }^{24}$ Of these studies, 2119 citations did not meet the inclusion criteria. The full text of the remaining 115 articles was assessed. This resulted in 36 eligible articles included in the final analysis. The following data were collected from the eligible articles: publication year, study type, number of patients, primary cancer histology, and outcomes reported. We assessed the level of evidence in the included articles using the Oxford Cen- tre for Evidence Based Medicine Level of Evidence 2 classification system (http://www.cebm.net/ocebm-levelsof-evidence/). The risk of bias was not assessed because most included studies were retrospective case series that have strong inherent bias. Following initial review, studies were categorized into one or more of the following categories: predictors of survival, predictors of ambulation, surgical technique, neurological function, primary tumor histology, and miscellaneous outcomes.

\section{Results \\ Study Characteristics}

A total of 36 studies met inclusion and exclusion criteria. Of the 36 included studies, 8 were prospective studies and 28 were retrospective studies. The year of publication ranged from 1992 to 2015. Study size ranged from 21 to 711 patients. Data extracted from these reports are presented in Tables 1-6.

\section{Predictors of Survival}

Nineteen studies reported predictors of survival for patients with spinal metastases who underwent decompression surgery (Table 1). . $3,3,7,15,18,19,21,25,28,30-32,34,35,37,38,40,43_{\text {Of }}$ these, 16 studies were retrospective; 1 was a longitudinal observational study; 1 was a randomized, multiinstitutional, nonblinded trial; and 1 was a semiprospective study that included both retrospectively and prospectively collected data. Surgical interventions included decompression with and without instrumentation and radiotherapy. Primary histology of tumors varied widely; however, prostate cancer (14 studies), lung cancer (13 studies), breast cancer (10 studies), and renal cancer (6 studies) were commonly reported in the included studies.

In a multivariable analysis of 105 patients with predominantly lung cancer as the primary tumor site, Chong et al. ${ }^{5}$ found that a limited number $(<3$ levels) of spinal metastases and postoperative adjuvant therapy (local irradiation only, chemotherapy only, or irradiation and systemic chemotherapy) were associated with increased survival (HR of 0.53 and 0.48 , respectively, both $\mathrm{p}<$ $0.05)$. Padalkar et al. ${ }^{28}$ studied 102 patients and found that metastases to internal organs $(\mathrm{p}<0.001)$ and increased number of extraspinal bony metastases $(p<0.01)$ were significantly associated with worse odds of survival. In a longitudinal observational study, Park et al. ${ }^{31}$ used a multivariable analysis to find that time to neurological deficit (risk ratio $[R R] 2.28, p=0.02$ ), postoperative chemotherapy (RR 6.58, p < 0.001), and postoperative Eastern Cooperative Oncology Group (ECOG) performance status (RR $2.73, \mathrm{p}=0.04$ ) were independent predictors of increased survival time. No study reported a significant effect of time-to-surgery following the onset of spinal cord compression symptoms on survival. ${ }^{36}$ Quraishi et al. ${ }^{36}$ reported that there was no significant difference between 3 groups treated with surgery within 24 hours, between 24 and 48 hours, and over 48 hours from acute presentation of neurological symptoms with respect to survival $(p=0.99)$. Finally, in a randomized, multiinstitutional, nonblinded trial, Patchell et al. ${ }^{32}$ found that surgical treatment followed by radiotherapy compared with radiotherapy alone resulted 


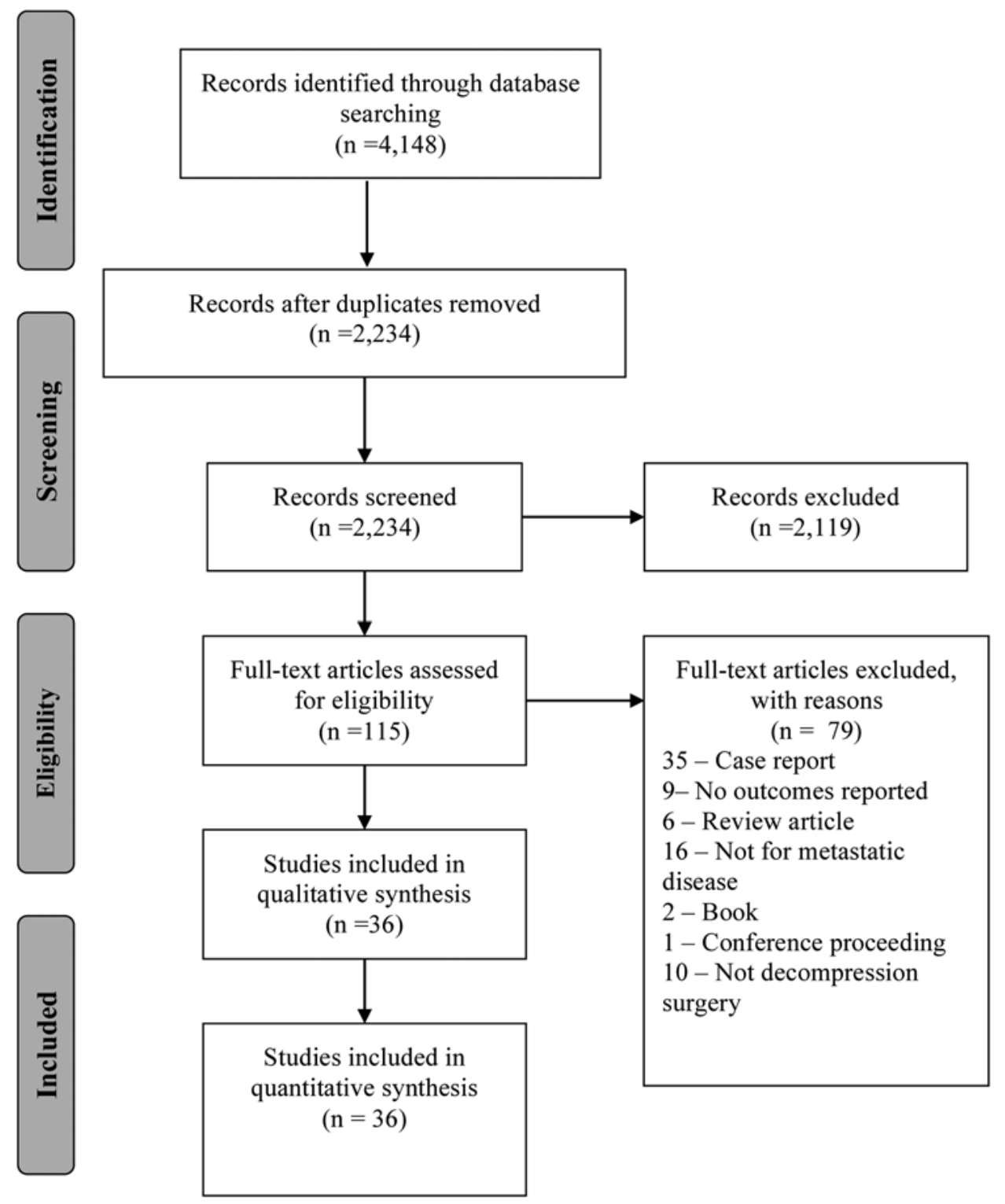

FIG. 1. PRISMA flow diagram for selection of studies based on inclusion criteria during systematic review.

in increased median survival time (126 days vs 100 days, respectively; RR 0.6, $\mathrm{p}=0.03$ ).

Several studies established scoring systems for prediction of survival following decompression surgery for various primary tumor sites. Crnalic et al. ${ }^{7}$ established a scoring system for prediction of survival following decompression surgery based on the results of survival analyses of patients with prostate cancer metastatic to the spine. The authors included the hormone status of patients' prostate cancer, preoperative Karnofsky Performance Status (KPS), evidence of visceral metastasis, and preoperative serum prostate-specific antigen (PSA) in calculating the new prediction score. ${ }^{7}$ The authors found that hormone status was strongly associated with survival in their patients as well as in 2 other studies of spinal cord compression in patients with prostate cancer. Consequently, the authors assigned maximal weight to hormone status in their score. ${ }^{7}$ Additionally, the authors noted that KPS was the strongest predictor of survival in the their hormonerefractory patients?

Lei et al. ${ }^{21}$ sought to establish a scoring system for survival and functional outcome among patients undergoing posterior decompression surgery for lung cancer metastatic to the spine. The authors found that preoperative ambulatory status $(\mathrm{p}<0.01)$, visceral metastases $(\mathrm{p}<$ $0.001)$, and time to developing motor deficits $(\mathrm{p}<0.001)$ were significant predictors of survival and were therefore included in the scoring system. ${ }^{21}$ In a separate study, Lei et al. ${ }^{19}$ also created a scoring system to predict survival prognosis among patients with metastatic non-small cell lung cancer causing spinal cord compression who underwent surgical decompression. The authors included the following components as part of their scoring system: ECOG performance status $(\mathrm{p}=0.02)$, number of involved verte- 


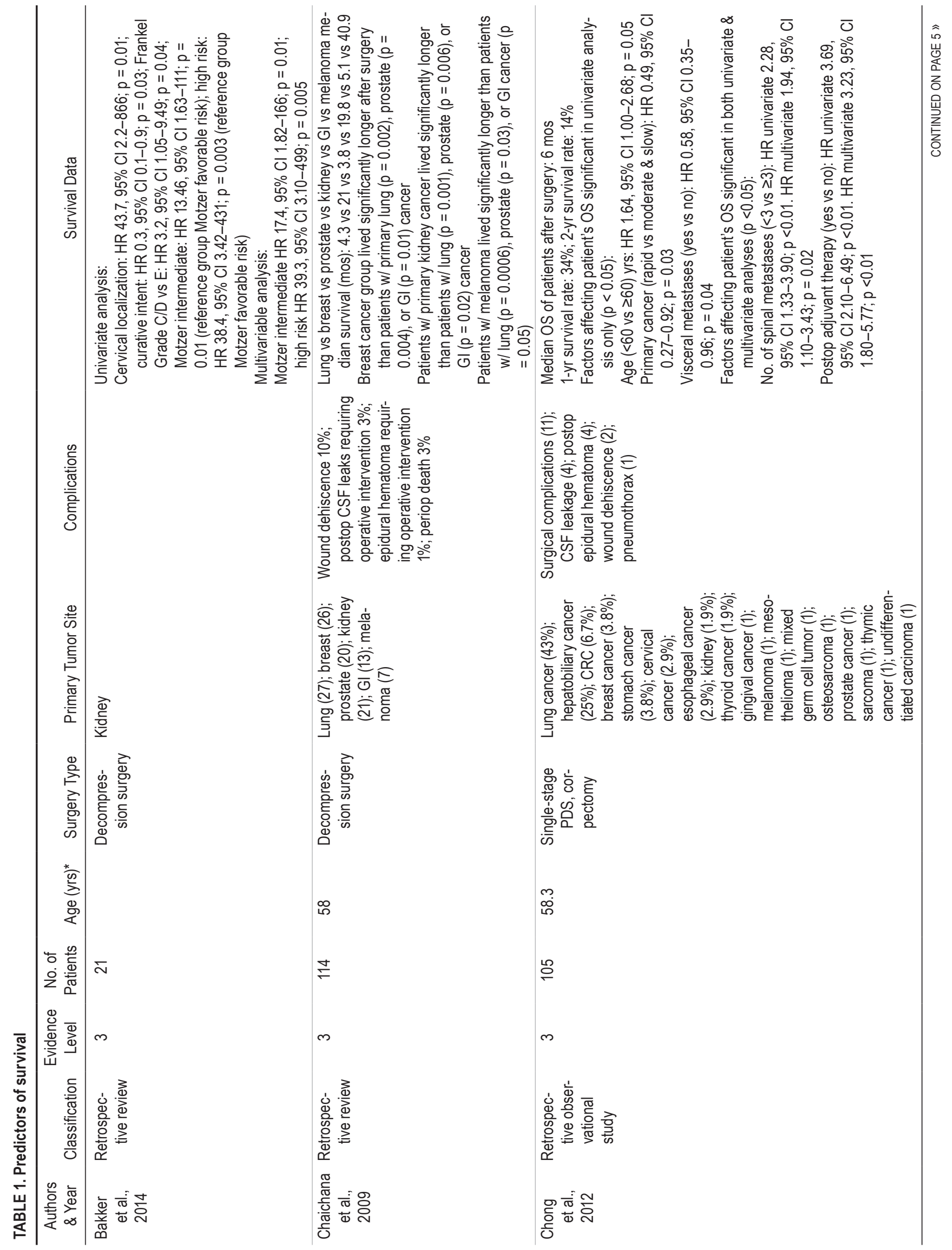




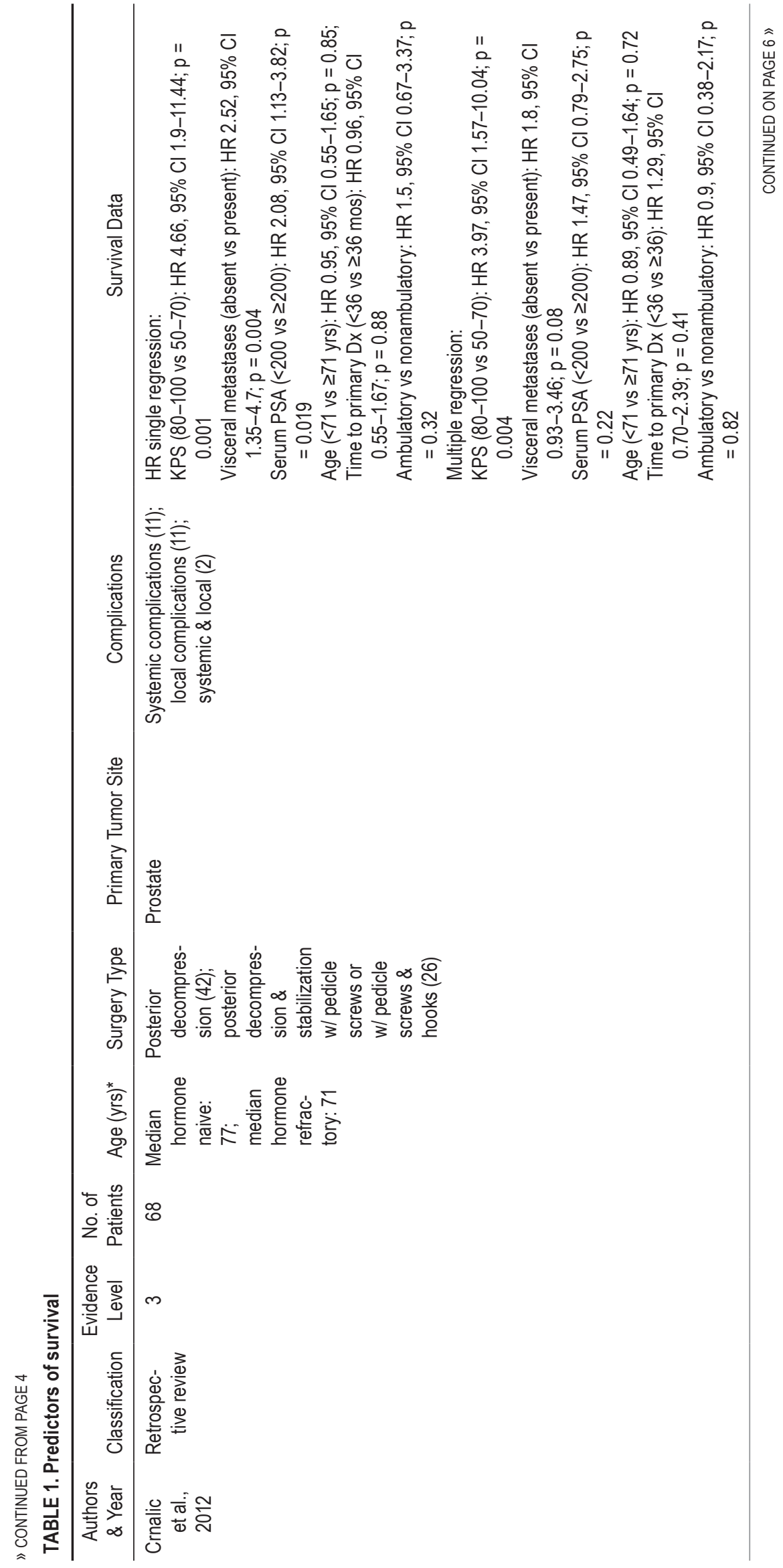




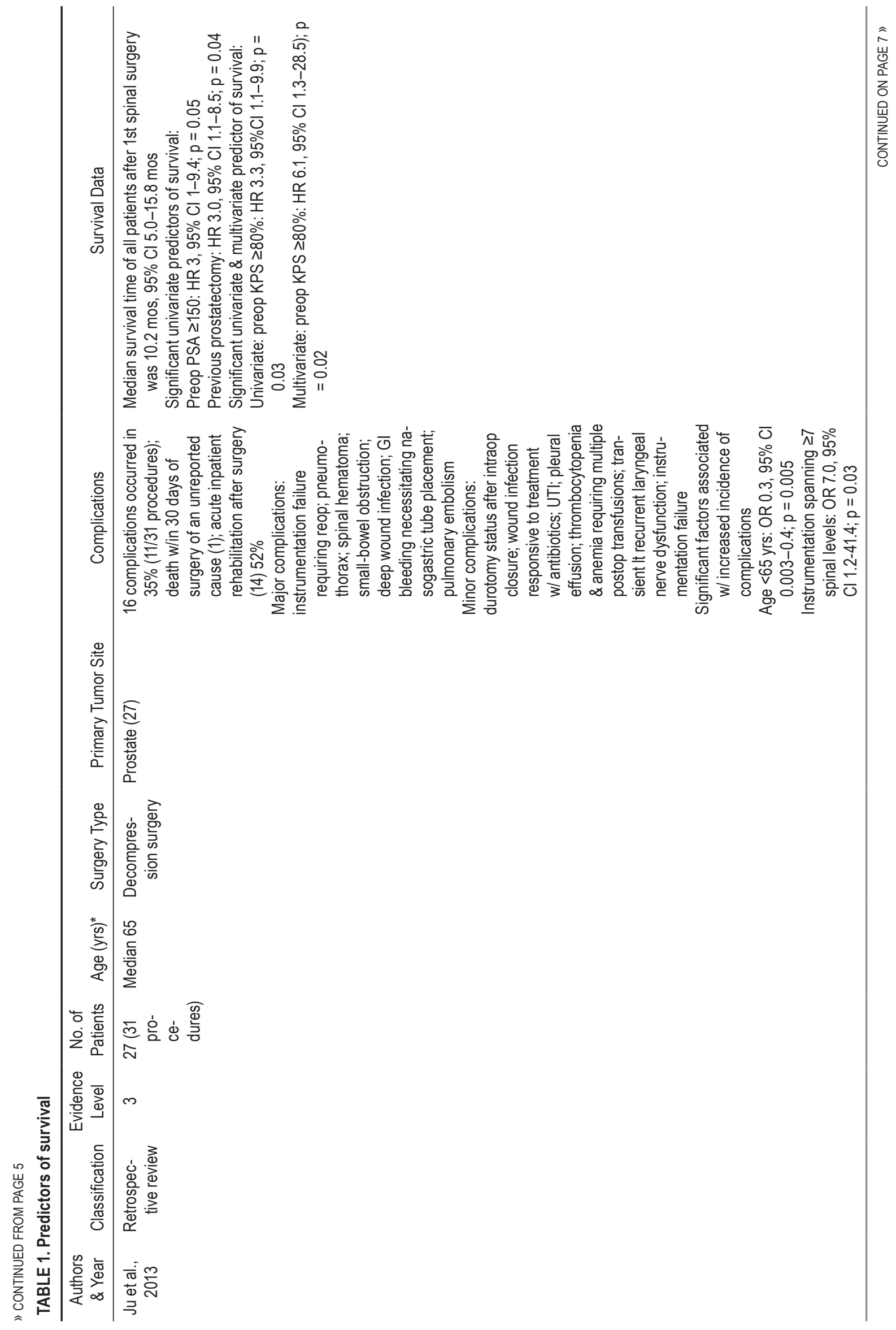




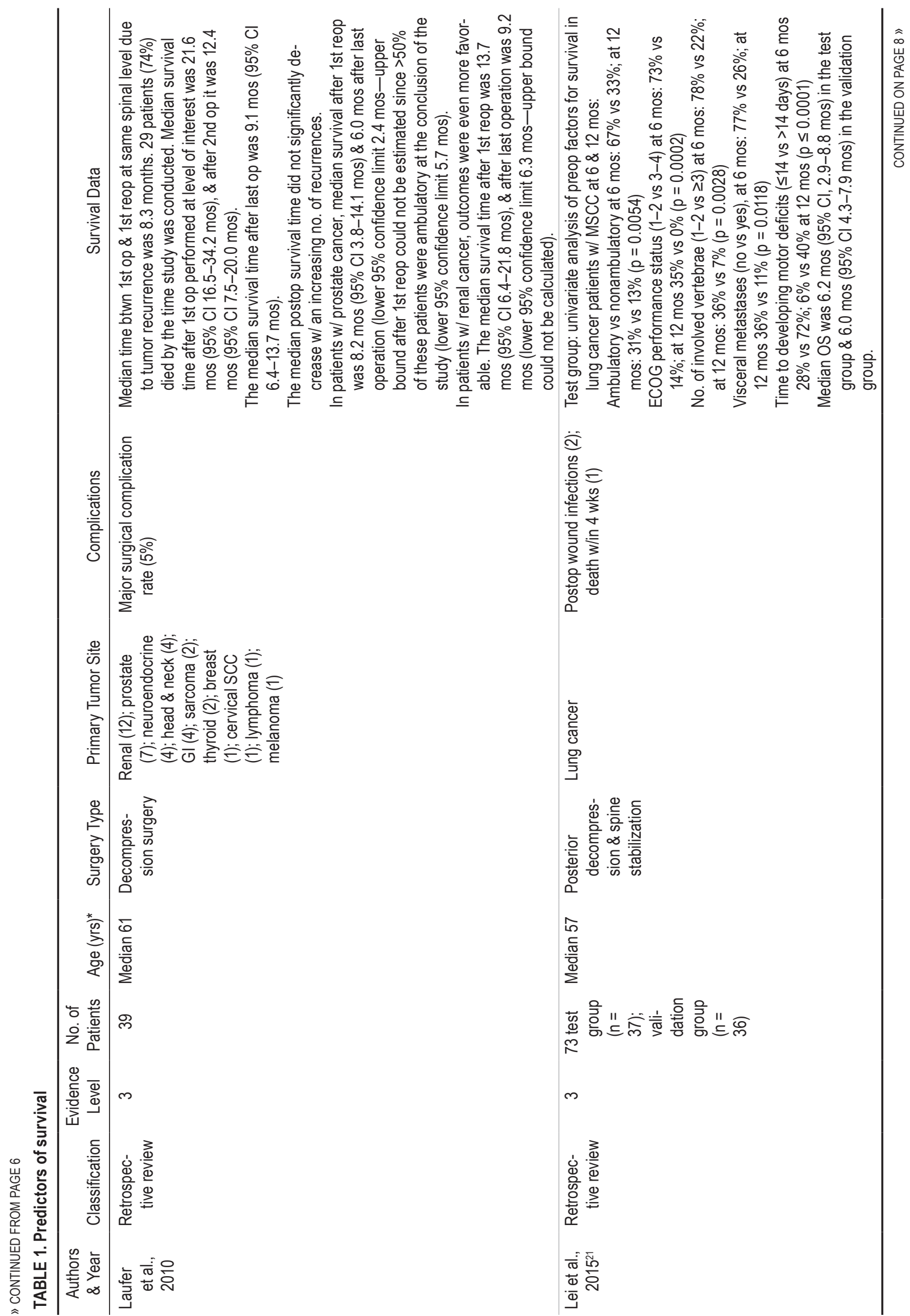

Neurosurg Focus Volume 41 • August 2016 


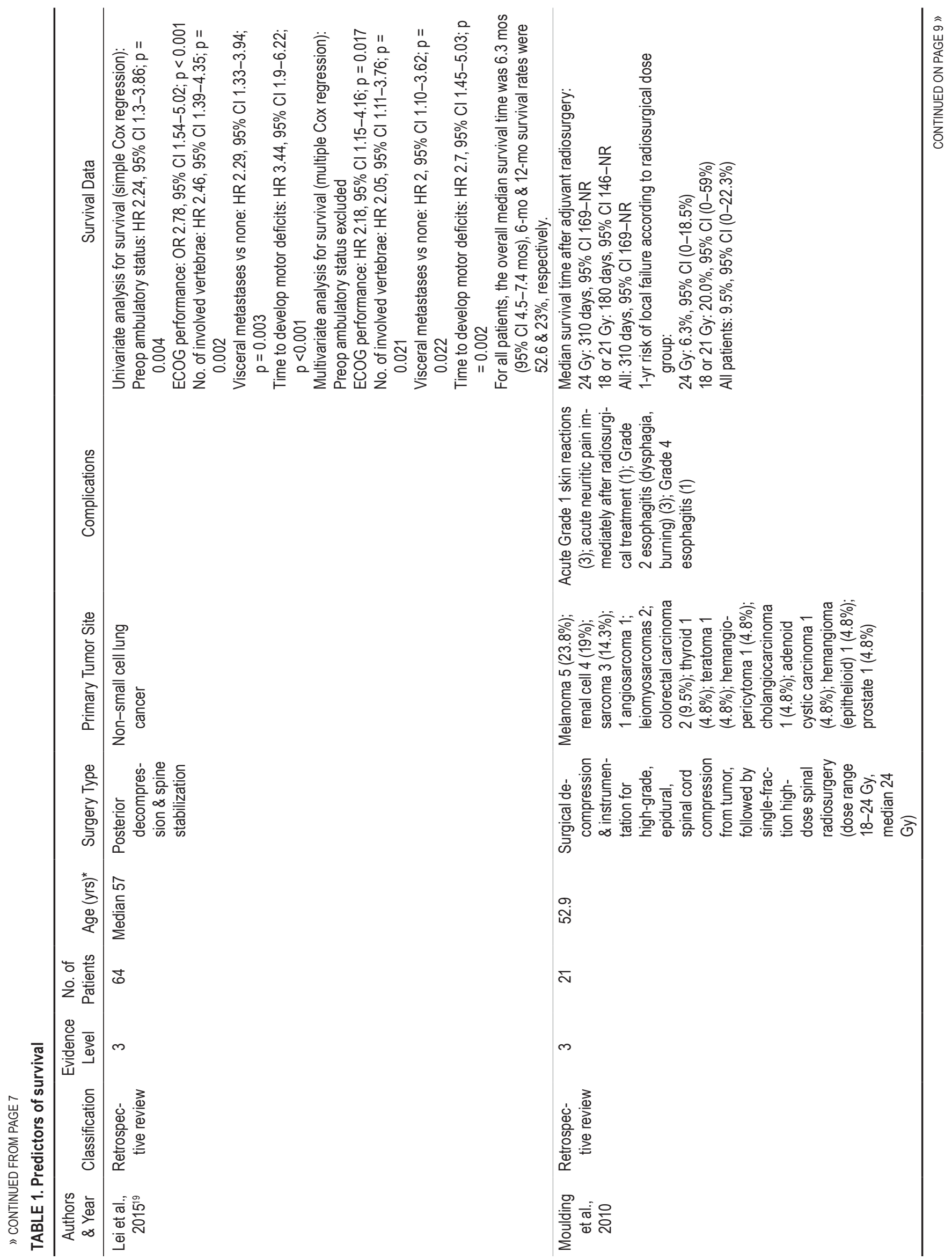




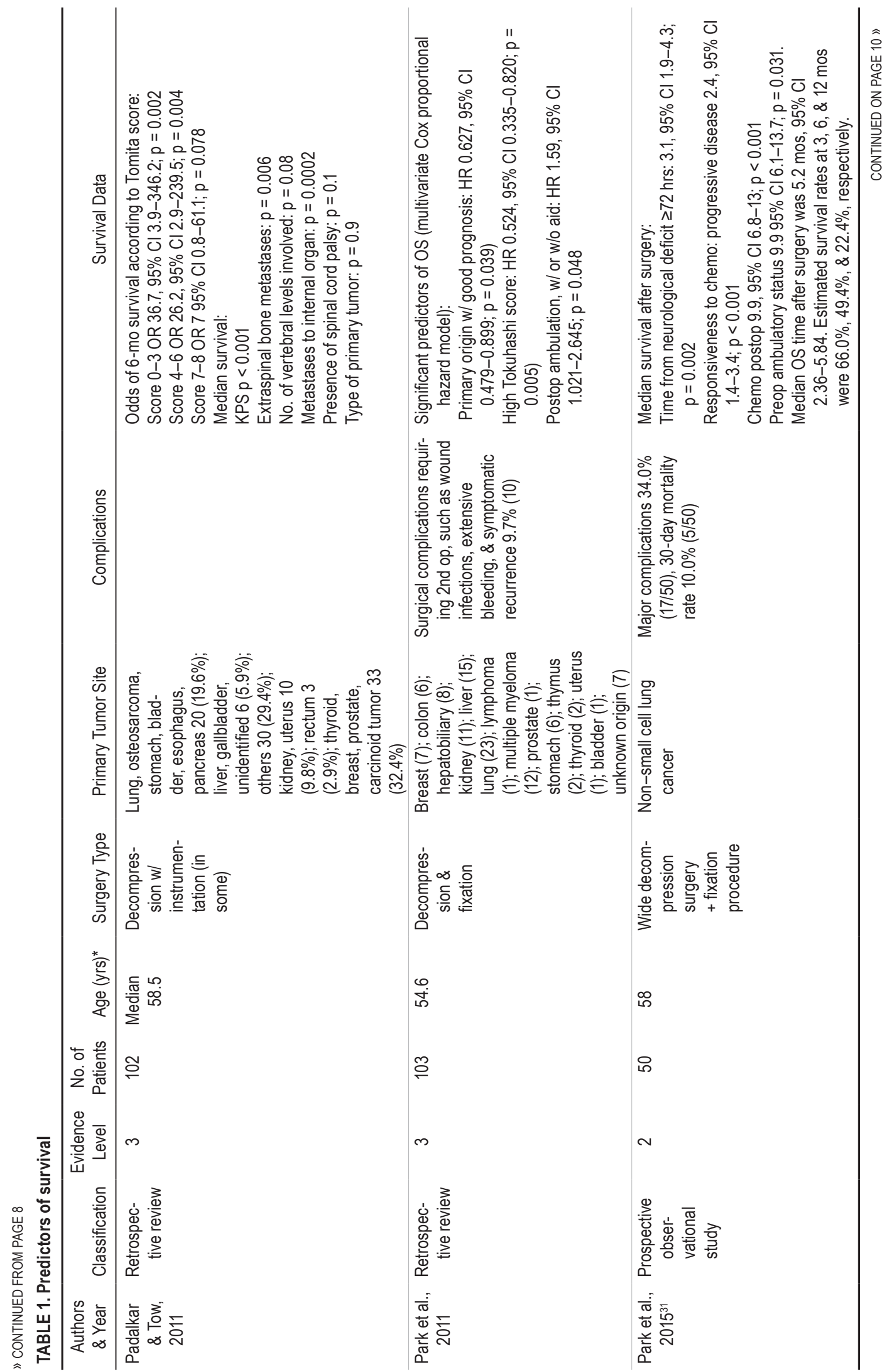




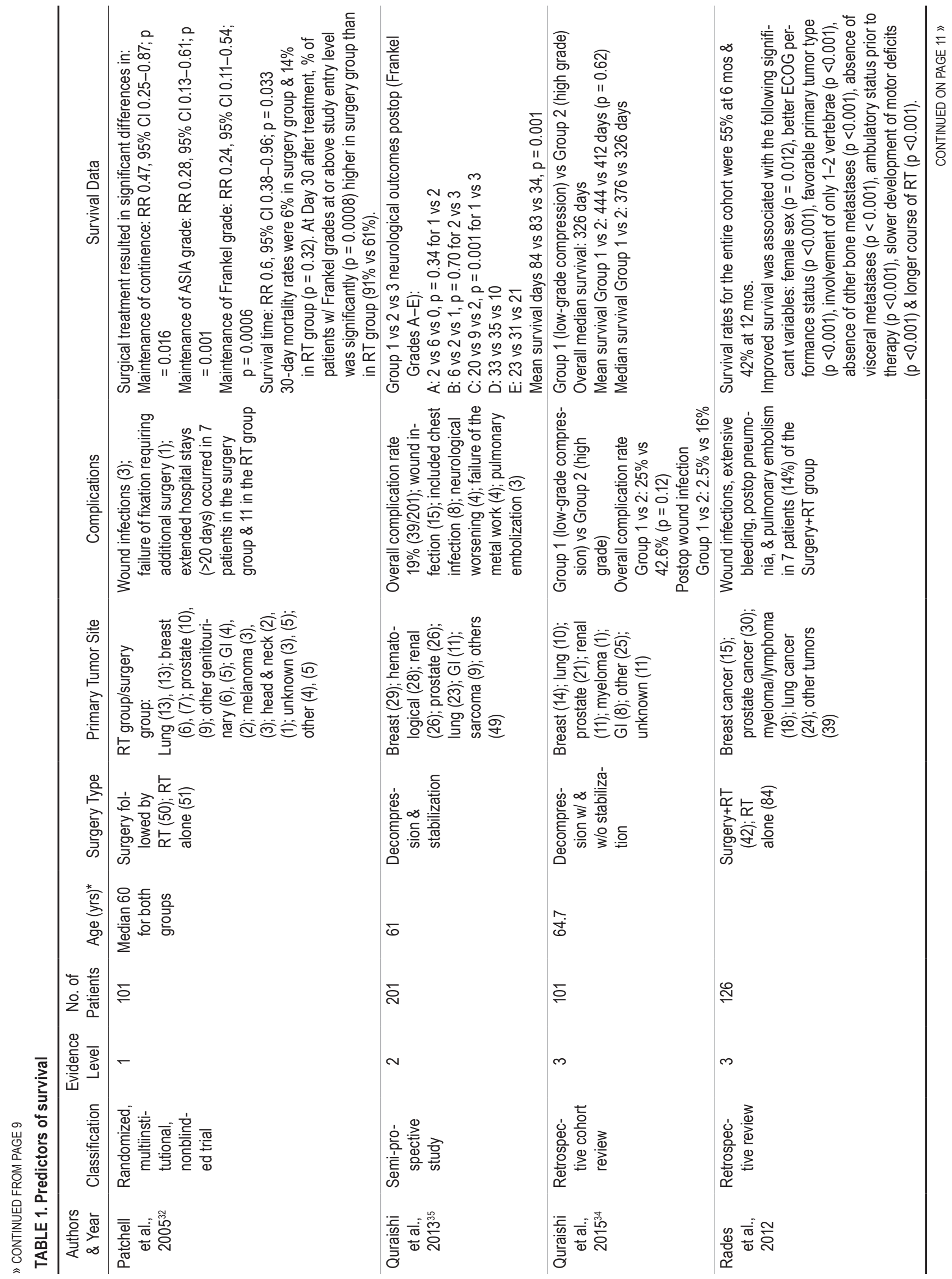




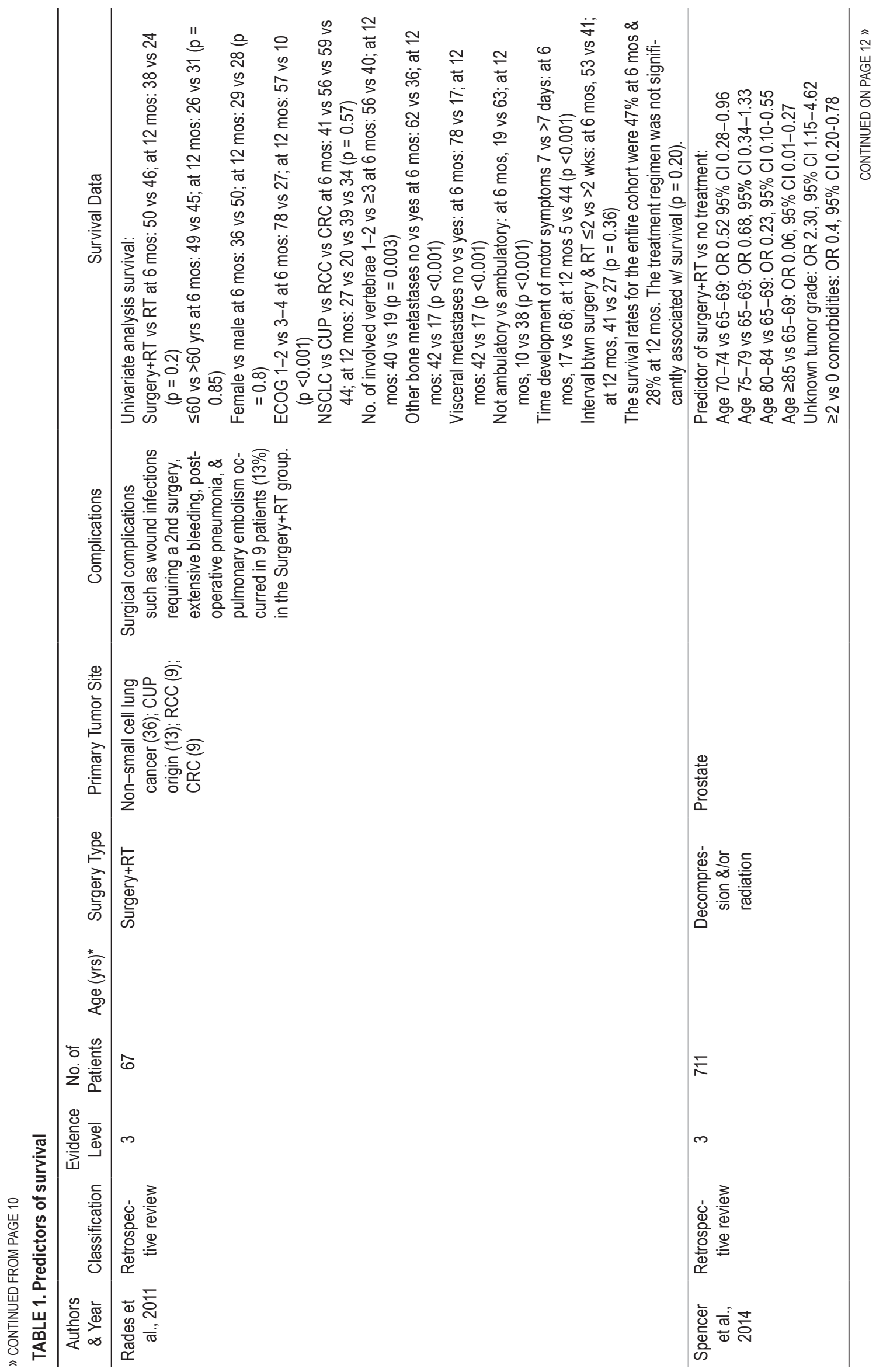




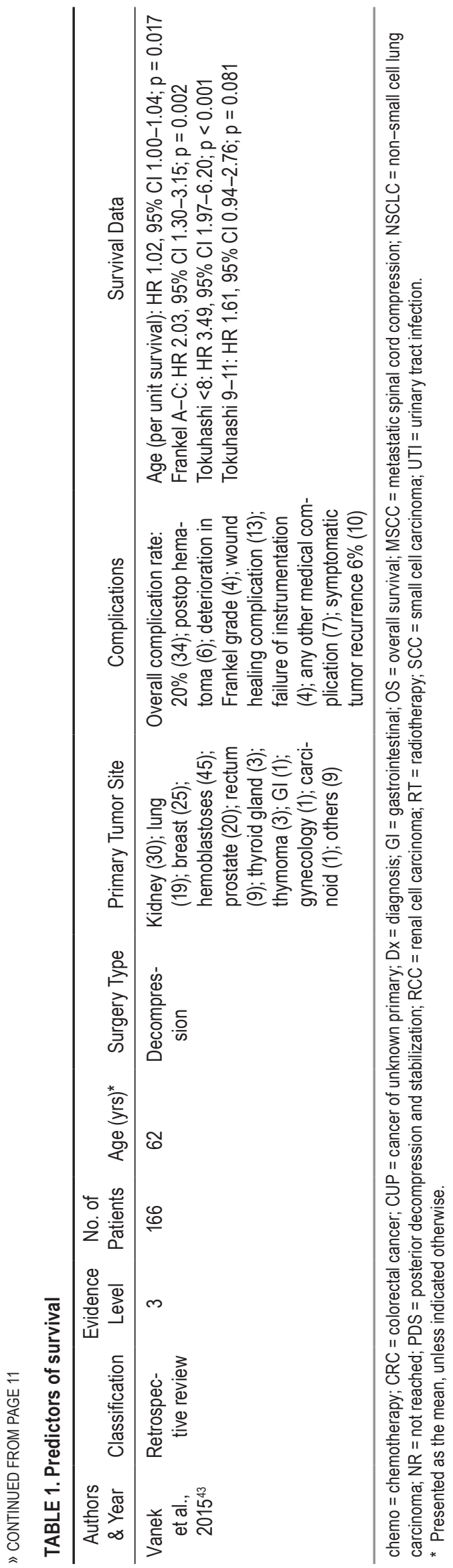

brae $(p=0.02)$, visceral metastases $(p=0.02)$, and time to developing motor deficits $(\mathrm{p}<0.01)$.

Three studies found that good preoperative KPS ( $\geq$ $80 \%$ ) was a significant predictor of survival.,15,28 Padalkar and $\mathrm{Tow}^{28}$ determined that a high preoperative KPS was significantly associated with increased median survival times (median survival 13 months [95\% CI 10.0-16.0 months]) compared with a moderate (50\%-70\%) KPS (median survival 4 months [95\% CI 2.0-6.0 months]) and a poor (10\%-40\%) KPS (median survival 2 months [95\% CI 1.0-3.0]) in patients treated with decompression and instrumentation for spinal metastases $(\mathrm{p}<0.001)$.

Two studies investigated survival based on Tokuhashi scores. Park et al..$^{30}$ reported that the median overall survival times were significantly longer in patients with high (9-11) preoperative Tokuhashi scores (15.0 months [95\% CI 9.3-20.7 months]) relative to patients with low (0-8) preoperative Tokuhashi scores $(9.0$ months [95\% CI 7.510.5 months]) ( $<<0.01)$. Similarly, Vanek et al. ${ }^{43}$ found that Tokuhashi scores were a significant and independent predictor of survival following decompression surgery for spinal metastases $(\mathrm{p}<0.001)$.

One study found an association between Motzer scores and survival. Bakker et al. ${ }^{2}$ determined that among patients with renal cell carcinoma metastatic to the spine, intermediate (HR 17.4 [95\% CI 1.82-166], $\mathrm{p}=0.01$ ) and high (HR 39.3 [95\% CI 3.10-499, p < 0.01]) Motzer scores were significantly associated with worse odds of survival (median survival of 6 months and 2 months, respectively).

\section{Predictors of Ambulatory Status or Motor Function}

Sixteen studies reported predictors of postoperative ambulatory status and motor function following decompression surgery for spinal metastases (Table 2). ${ }^{1,3,4,13,16-}$ 20,22,29-31,33,38,39 Fifteen studies were retrospective, and one was a longitudinal observational study. Eleven studies $1,3,4,18,20,22,29-31,33,39$ reported outcomes following surgery alone, and 5 studies ${ }^{13,16,17,19,38}$ reported the effects of decompression surgery with radiotherapy. Primary tumor sites included lung (15 studies), breast (13 studies), prostate (12 studies), gastrointestinal (8 studies), and renal (4 studies).

Eight studies reported that preoperative ambulatory or preoperative motor status was a significant predictor of postoperative ambulatory status (Table 2). 4,13,16,20,29-31,33 Chaichana et al. ${ }^{4}$ reported that preoperative ability to walk (RR 2.3 [95\% CI 1.3-4.4], $\mathrm{p}<0.01$ ) was a positive predictor of postoperative ambulatory status, whereas pathological compression fracture of the vertebral body (RR 0.5 [95\% CI $0.2-0.9], \mathrm{p}<0.01$ ) was a negative predictor of postoperative ambulatory status. ${ }^{4}$ Kondo et al. ${ }^{16}$ found that visceral metastases to vital organs $(\mathrm{p}<0.01)$, primary renal tumors $(\mathrm{p}=0.04)$, severe preoperative paralysis $(\mathrm{p}$ $<0.0001$ ), and poor preoperative performance status ( $\mathrm{p}<$ 0.0001 ) were significant negative predictors of postoperative ambulatory status among patients who received intraoperative radiotherapy combined with posterior decompression and stabilization. ${ }^{16}$ Ghogawala et al. ${ }^{13}$ determined that lower preoperative Frankel grade was a significant predictor of postsurgical ambulatory status $(\mathrm{p}<0.01)$. Lei et al. ${ }^{20}$ demonstrated that metastasis to the lumbar spine (OR 1.9 [95\% CI, 1.1-3.3], $\mathrm{p}=0.02$ ), better preoperative 


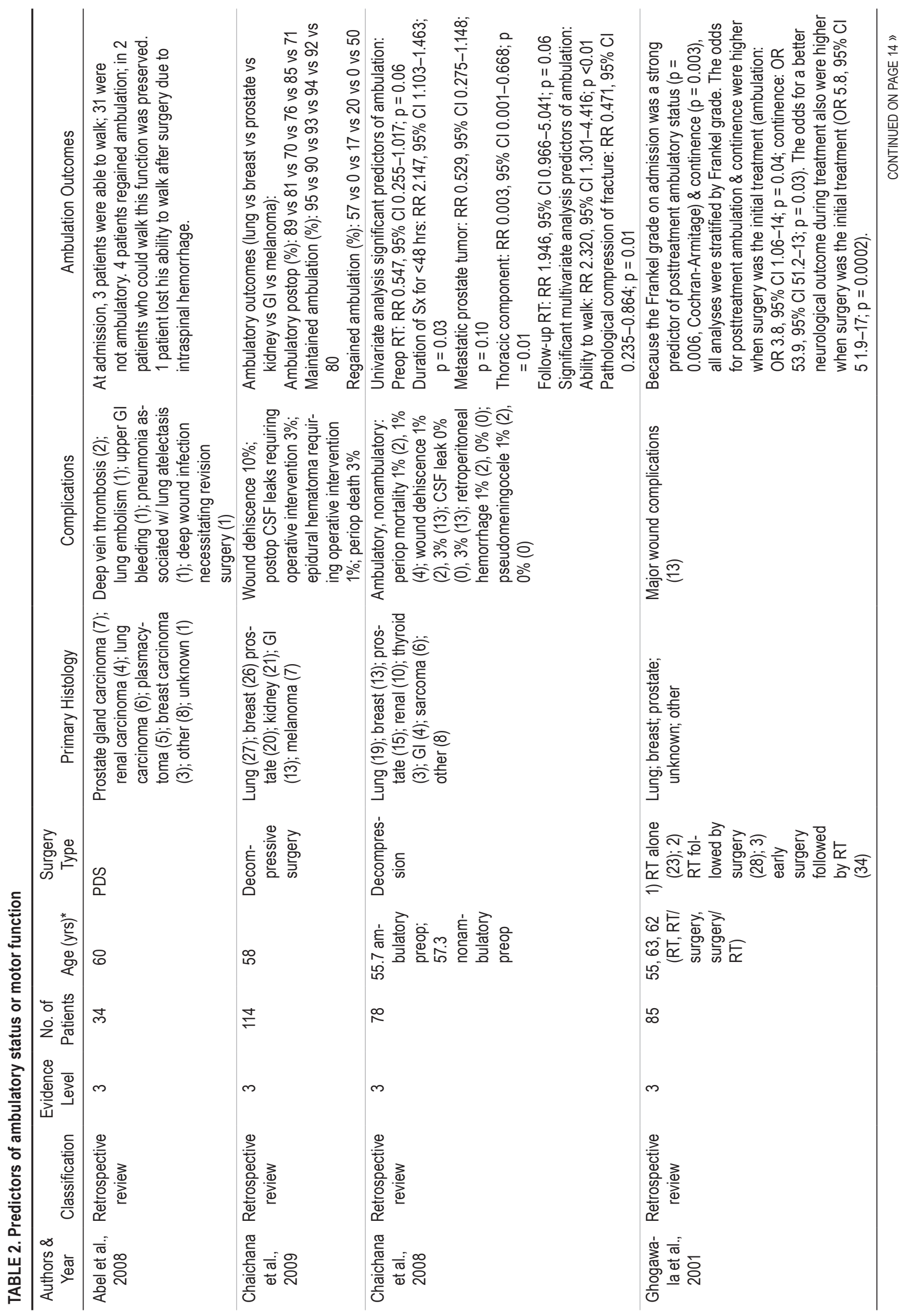




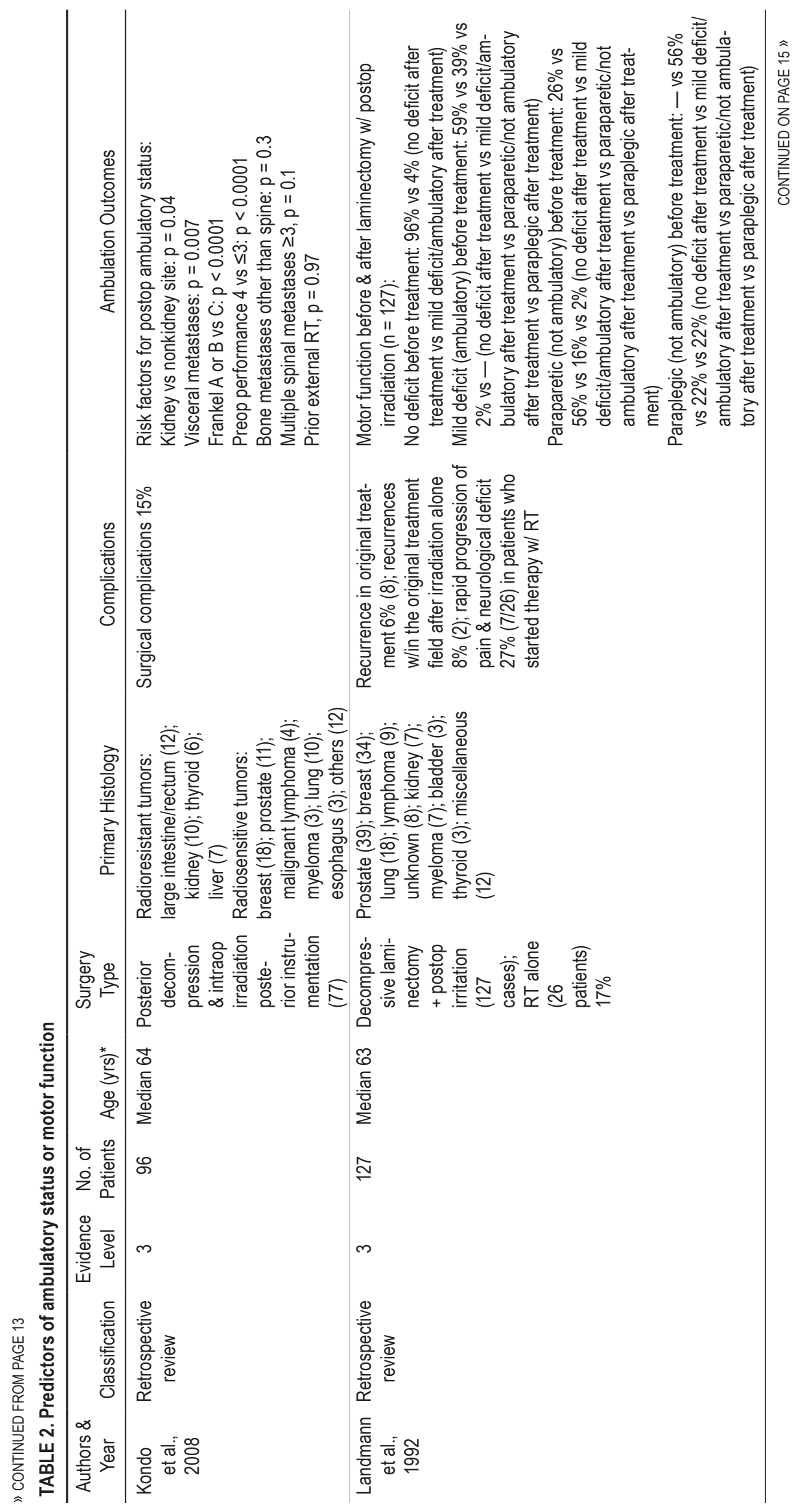




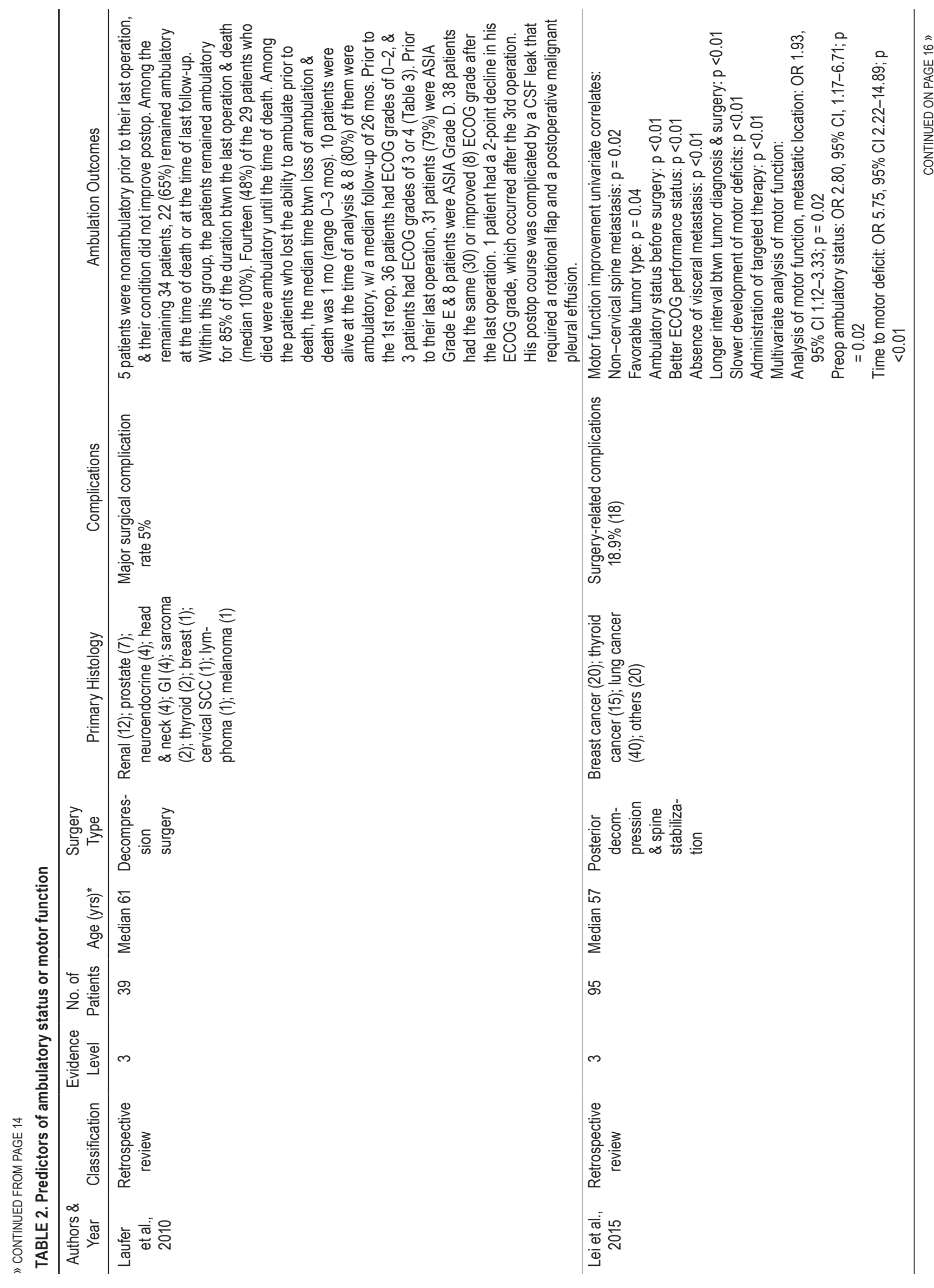




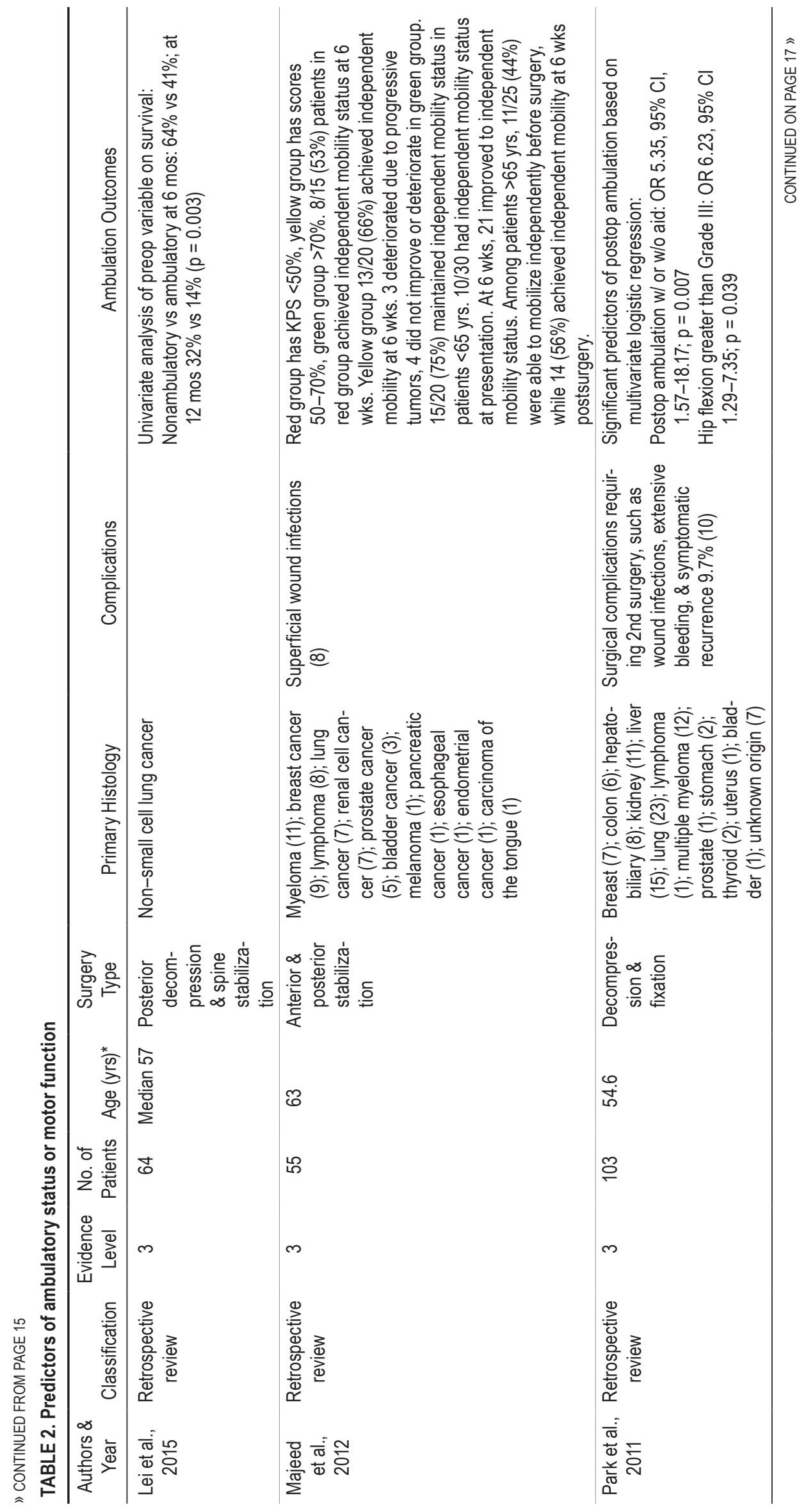




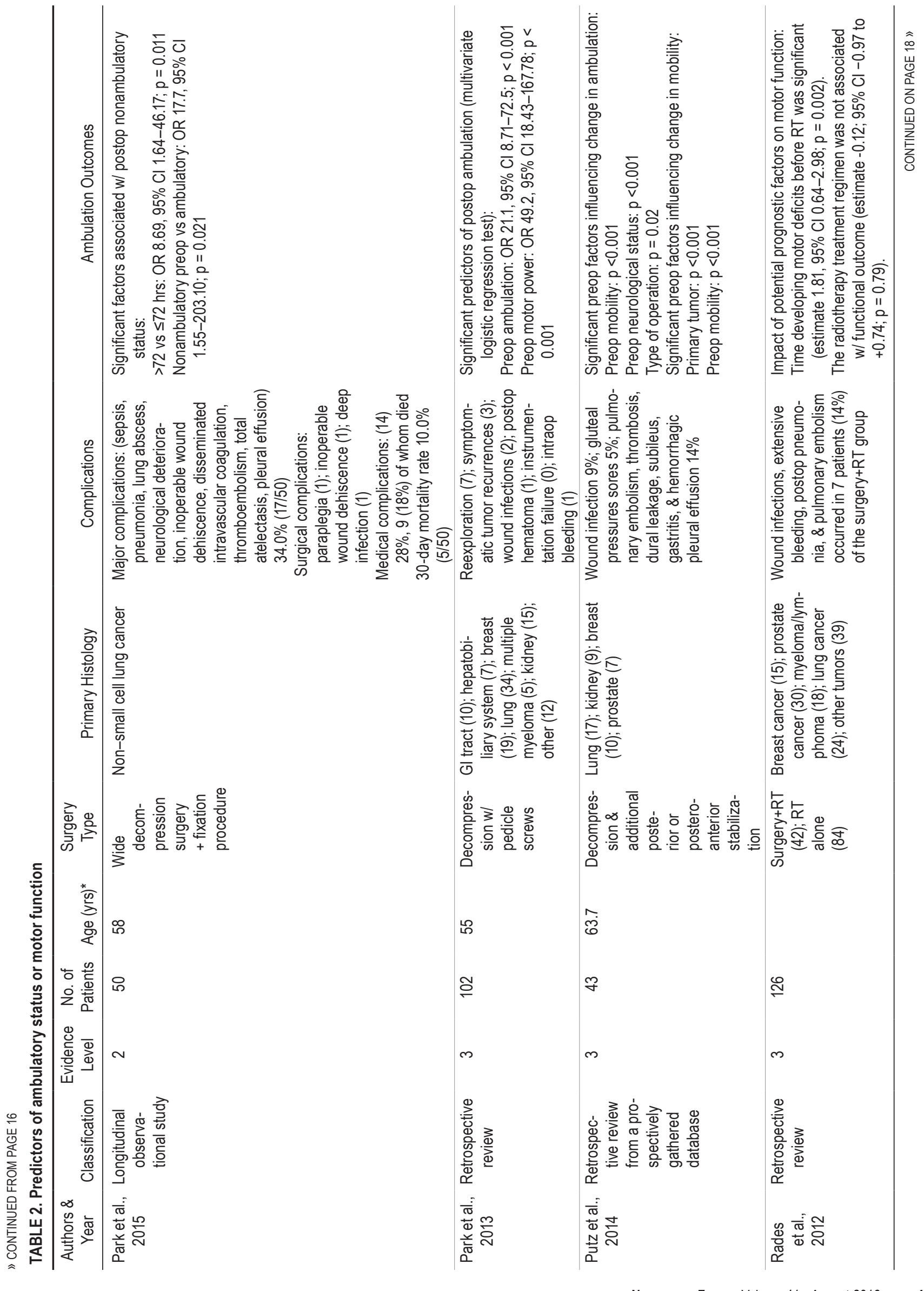




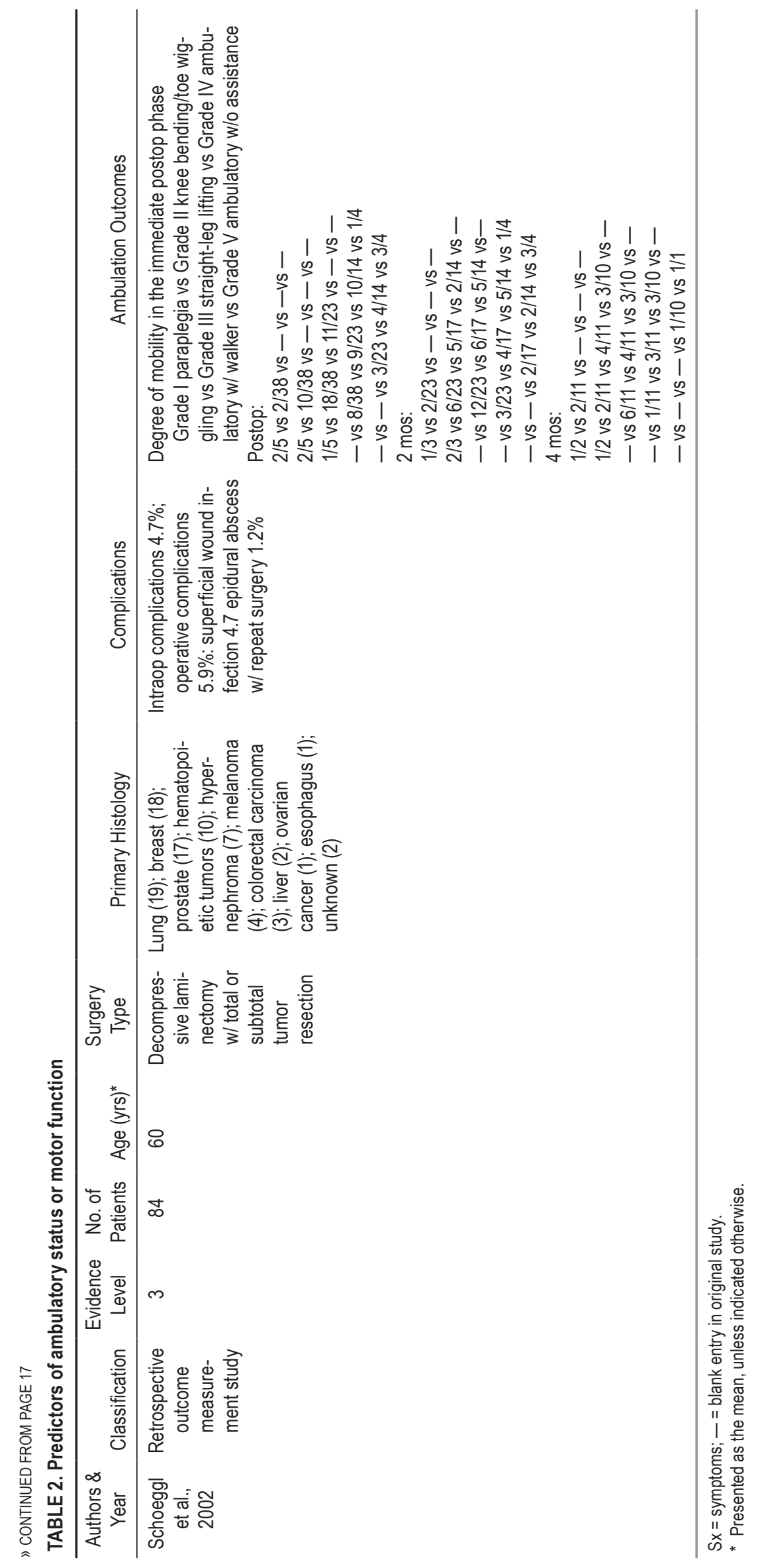




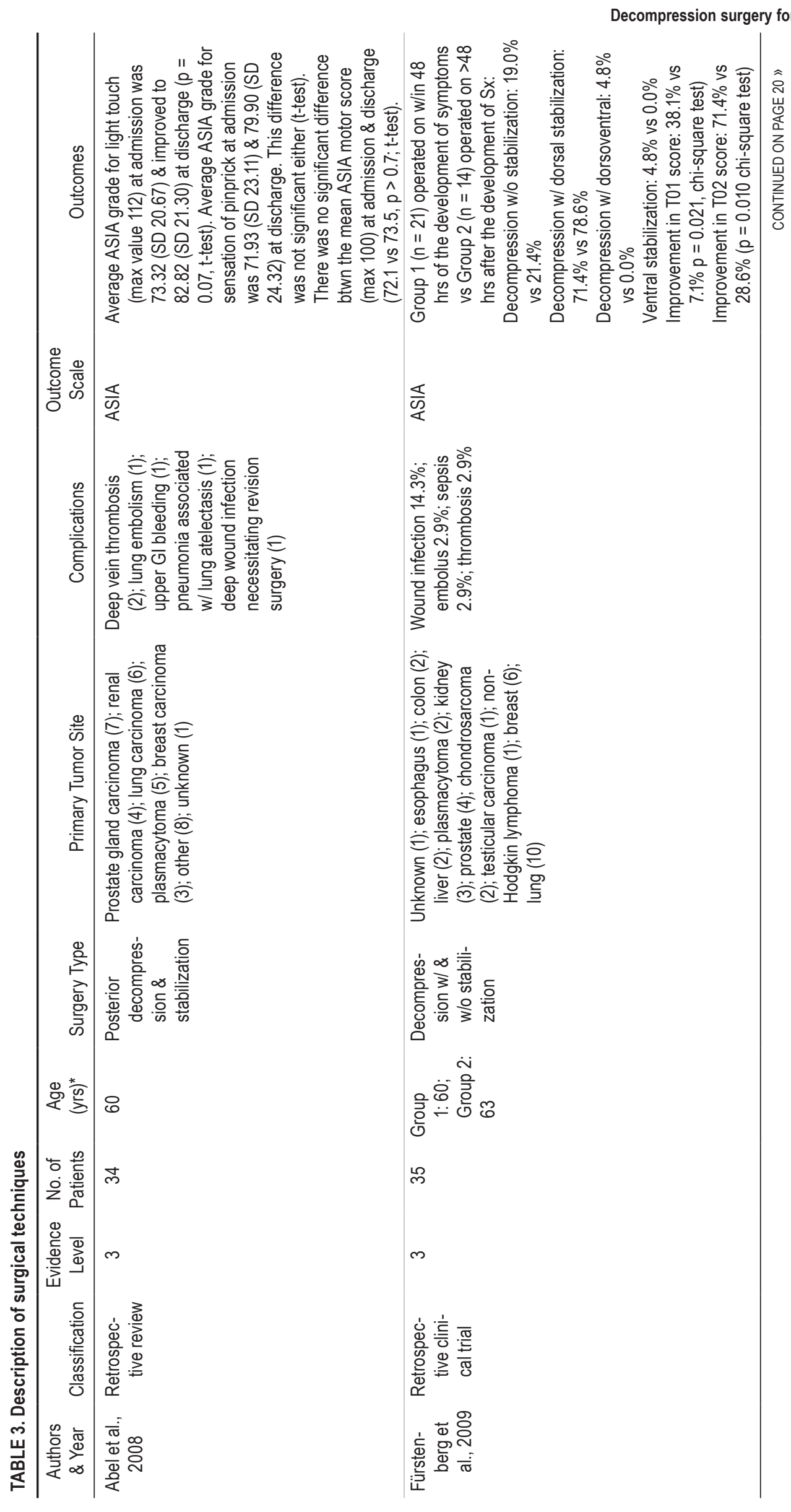




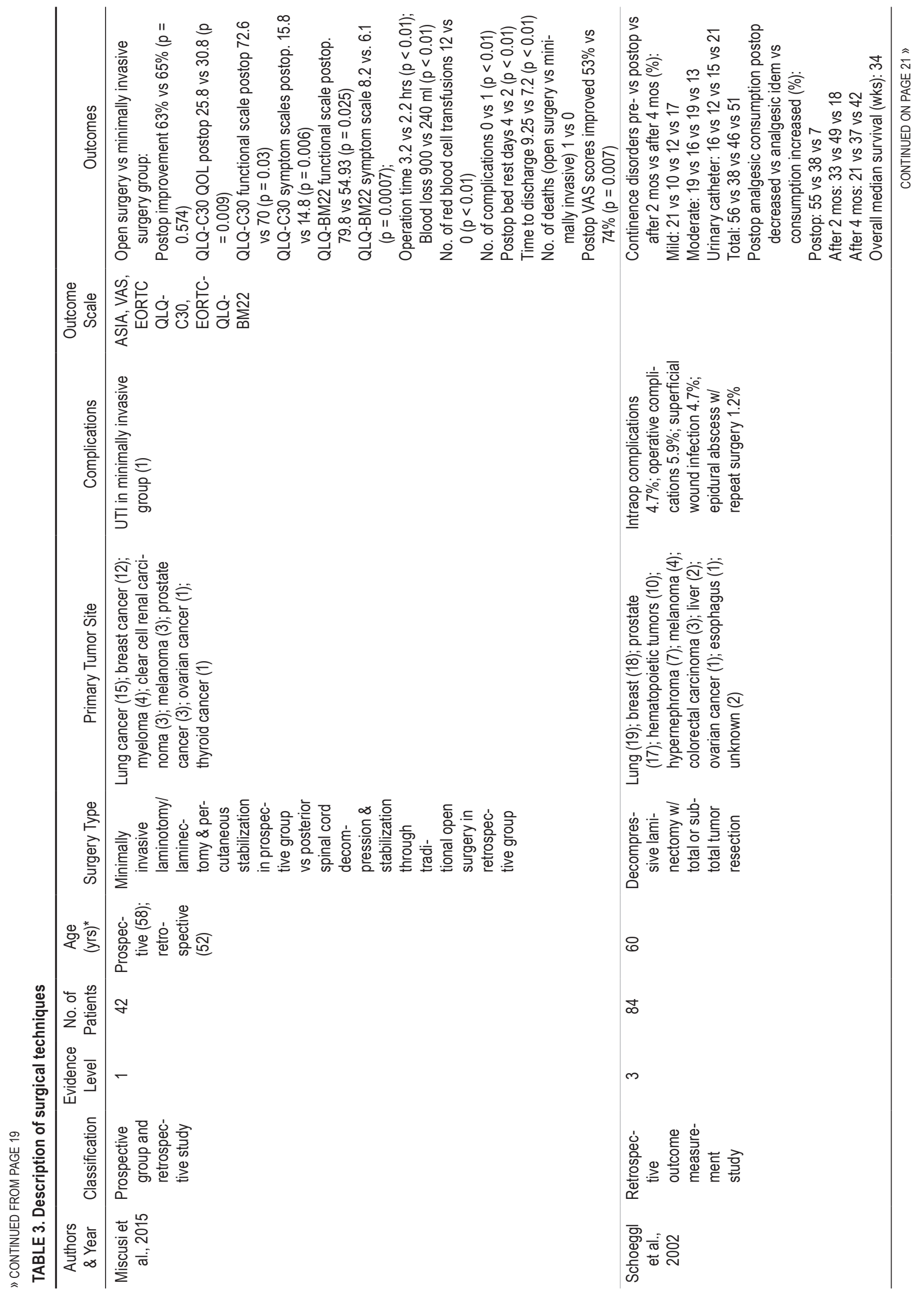




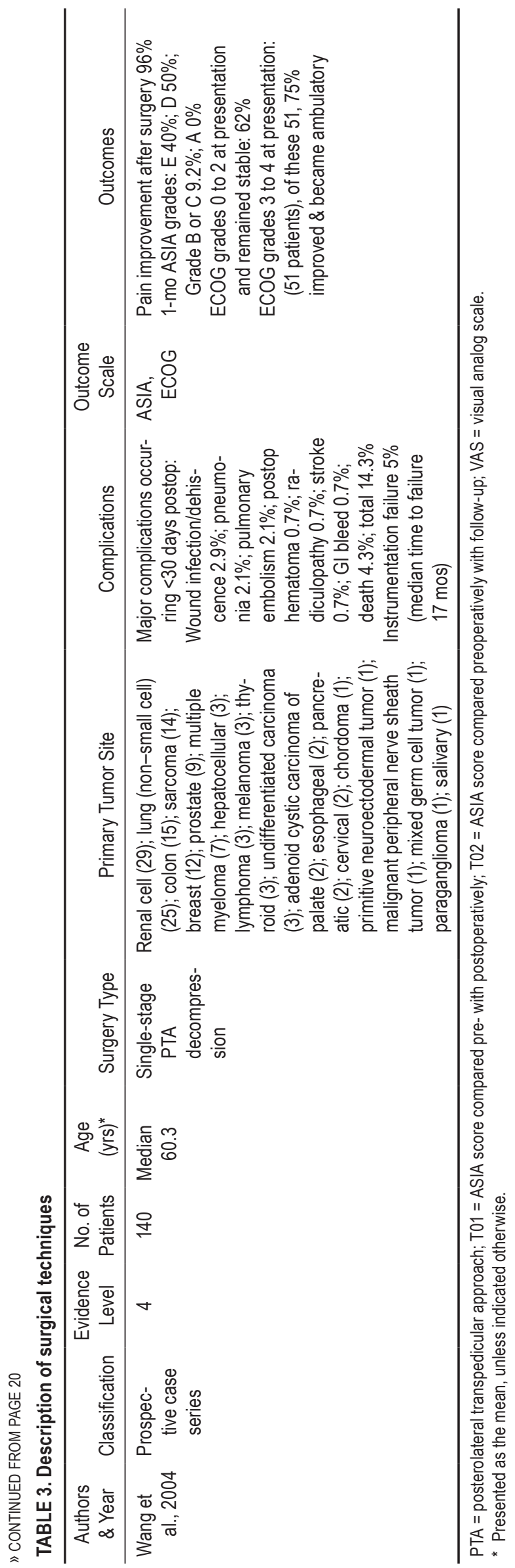

ambulatory status (OR 2.8 [95\% CI 1.2-6.7], $\mathrm{p}=0.02)$, and increased time to developing motor deficit (OR 5.8 [95\% CI 2.2-14.9], $\mathrm{p}<0.01$ ) were significant predictors of postoperative improvement in motor function. Utilizing a multivariable logistic regression analysis, Park et al. ${ }^{30}$ found that preoperative ambulation (OR 5.4 [95\% CI 1.6-18.2], $\mathrm{p}<0.01]$ ) and preoperative hip flexion power greater than Grade III (OR 6.2 [95\% CI 1.3-7.4], p = 0.04) were predictive of improved postoperative ambulation. Park et al..$^{29}$ found that preoperative lower-extremity power classification $(\mathrm{p}<0.001)$ and preoperative ambulation $(\mathrm{p}<0.001)$ significantly predicted postoperative ambulation. Finally, Chaichana et al. ${ }^{3}$ found that the primary lung histology was associated with increased odds of postoperative ambulation relative to all other primary tumor histologies.

\section{Description of Surgical Techniques}

Five studies compared outcomes following different surgical techniques for decompression surgery (Table 3). ${ }^{1,12,23,39,45}$ Three of the studies were retrospective and 2 were prospective. All 5 studies reported primary tumor sites of lung, prostate, and breast, and 4 studies reported primary renal cancers. The techniques reported on were posterior decompression and stabilization, posterior decompression without stabilization, and posterior decompression with total or subtotal tumor resection.,12,23,39,45 The outcomes measures used to compare surgical technique varied across the 7 included studies. Four studies used the American Spinal Injury Association (ASIA) Impairment Scale to assess neurological function. ${ }^{1,12,23,45}$

Two studies reported outcomes after decompression without stabilization. Schoeggl et al. ${ }^{39}$ reported results of decompressive laminectomy with total or partial tumor removal. The authors found that patients undergoing this technique experienced an improvement in their quality of life based on a reduction in analgesic consumption postoperatively and a decrease in the total percentage of patients experiencing continence disorders following surgery (Table 3). ${ }^{39}$ However, the technique did not improve quality of life outcomes for patients with preoperative paraplegia. ${ }^{39}$ Wang et al..$^{45}$ prospectively studied a consecutive series of 140 patients receiving single-stage posterolateral transpedicular decompression and reported a 96\% improvement in pain as measured through the visual analog scale score.

Two studies reported outcomes after minimally invasive decompressive surgery. Miscusi et al. ${ }^{23}$ prospectively studied 42 patients and compared minimally invasive surgery with standard open surgery for vertebral thoracic metastases and reported that there were no significant differences in postoperative ASIA score and complication rates between the 2 cohorts. However, the authors did note that the minimally invasive group had significantly less blood loss (240 ml vs $900 \mathrm{ml}, \mathrm{p}<0.01)$, shorter operation time (2.2 hours vs 3.2 hours, $\mathrm{p}<0.01$ ), and shorter bed rest length $(2$ days vs 4 days, $p<0.01)$ compared with the open surgery group. Furthermore, the authors also found that patients treated with minimally invasive surgery experienced a greater improvement in quality of life at 30-day follow-up based on the European Organisation for Research and Treatment of Cancer Quality of Life questionnaire (EORTC QLQ-30) $(\mathrm{p}<0.01)$ and EORTC Bone Me- 


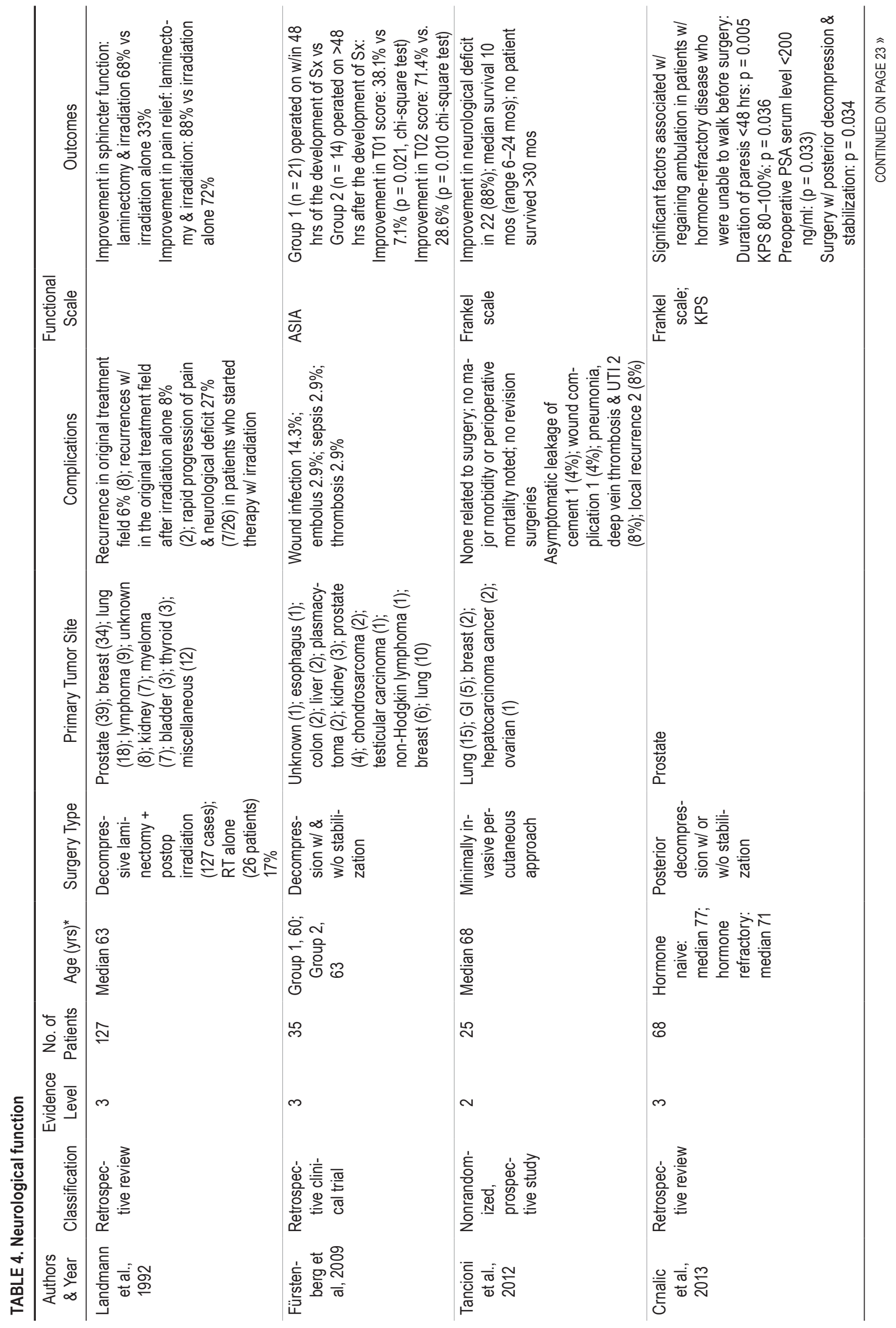




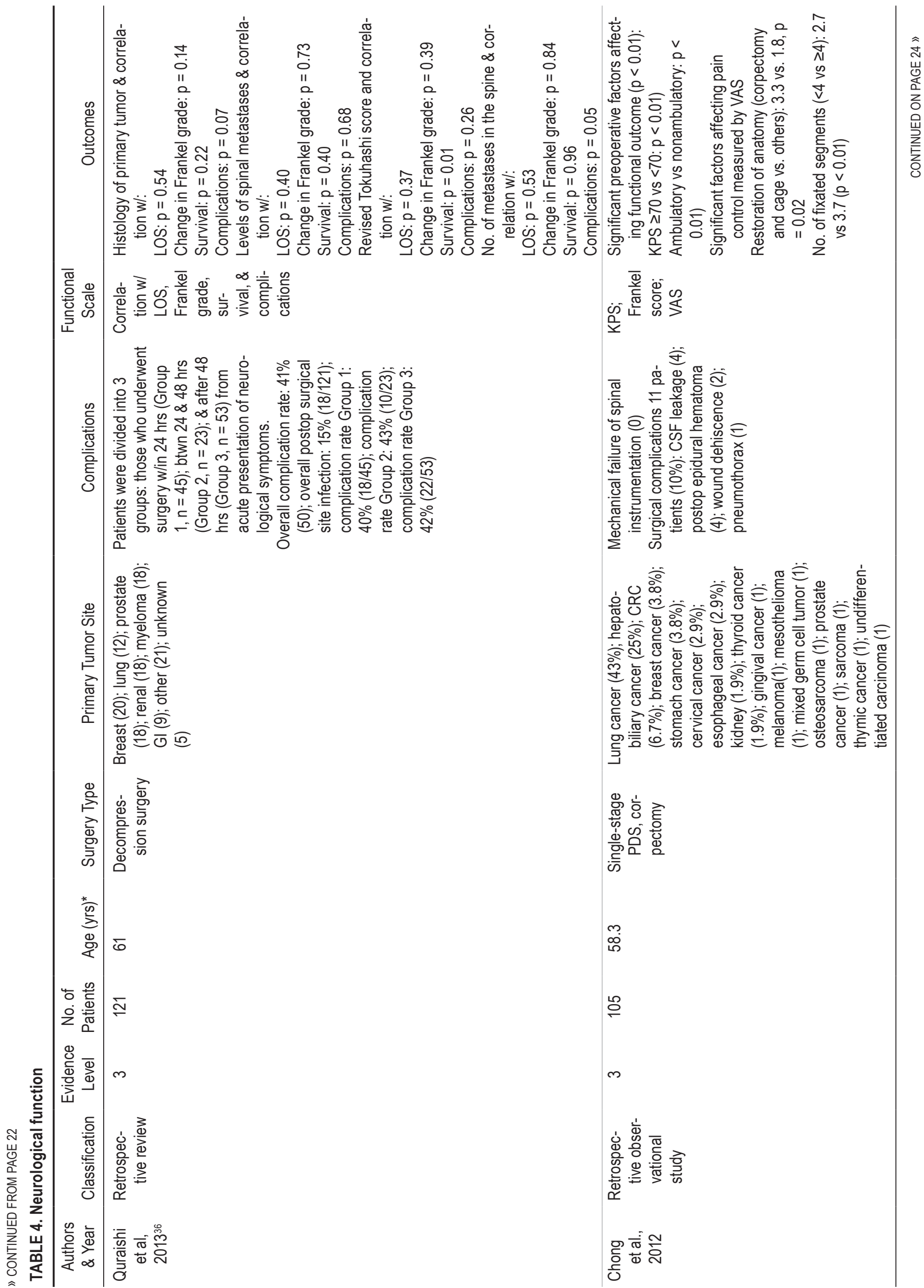

Neurosurg Focus Volume 41 • August 2016 


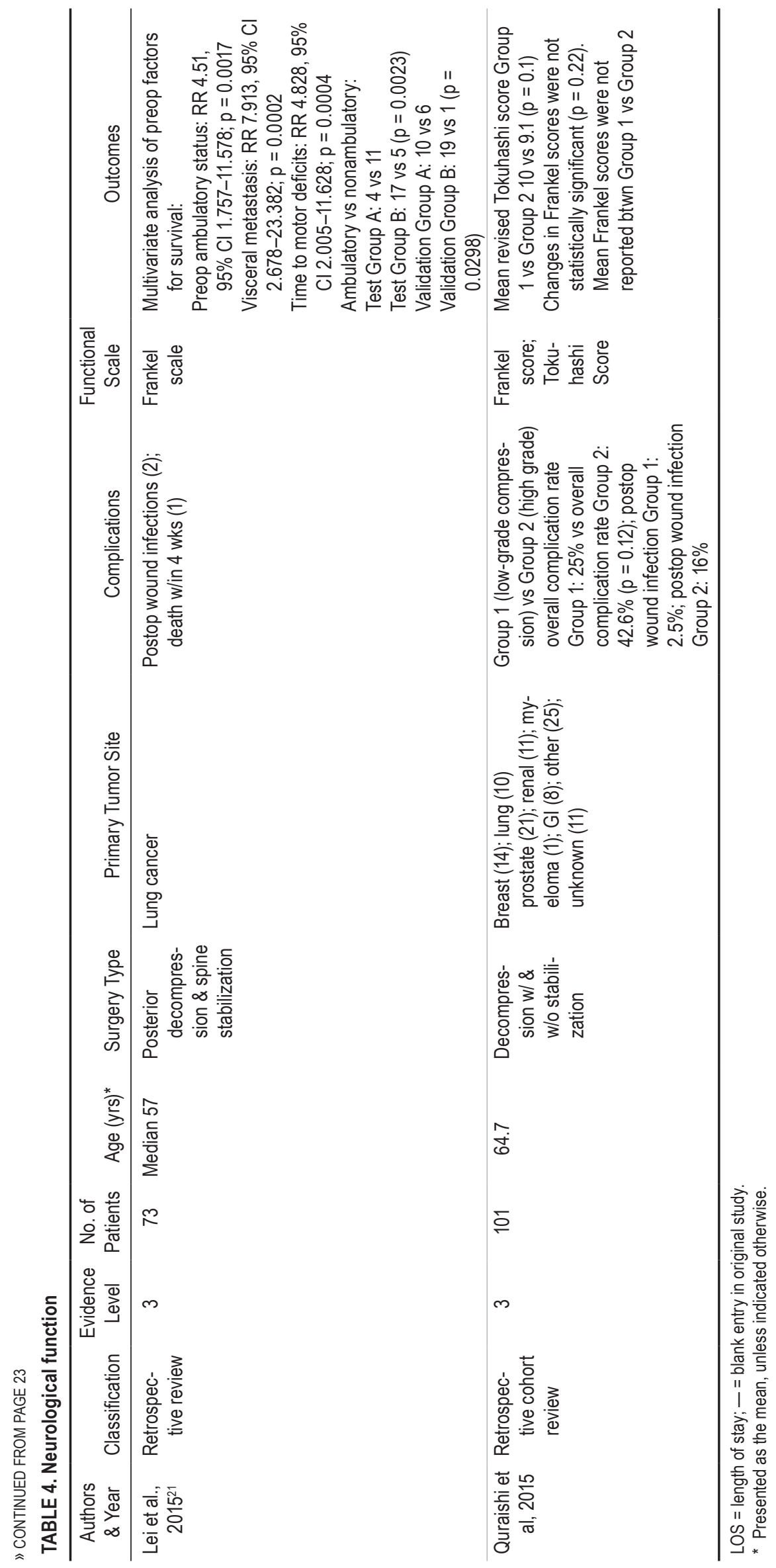




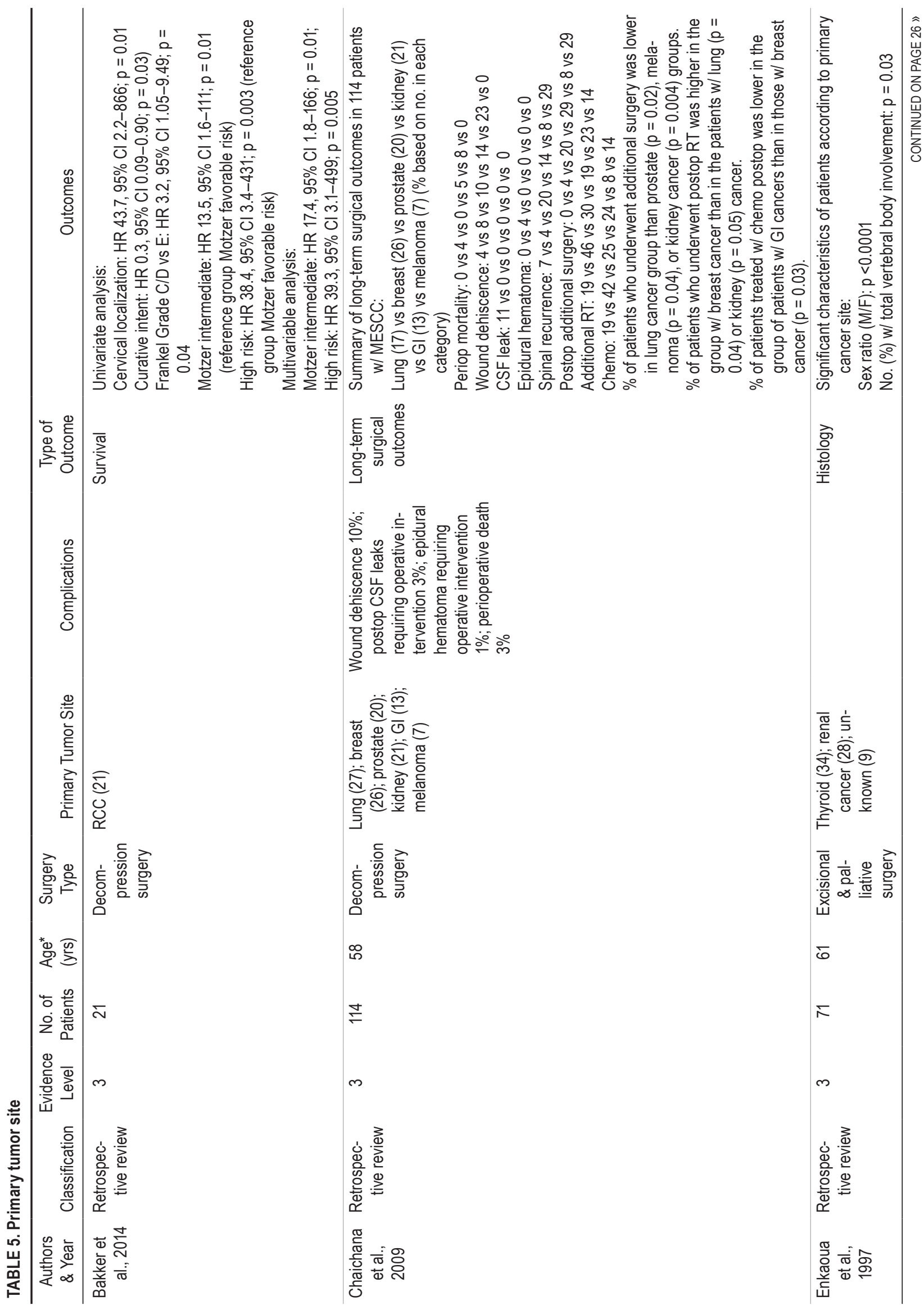




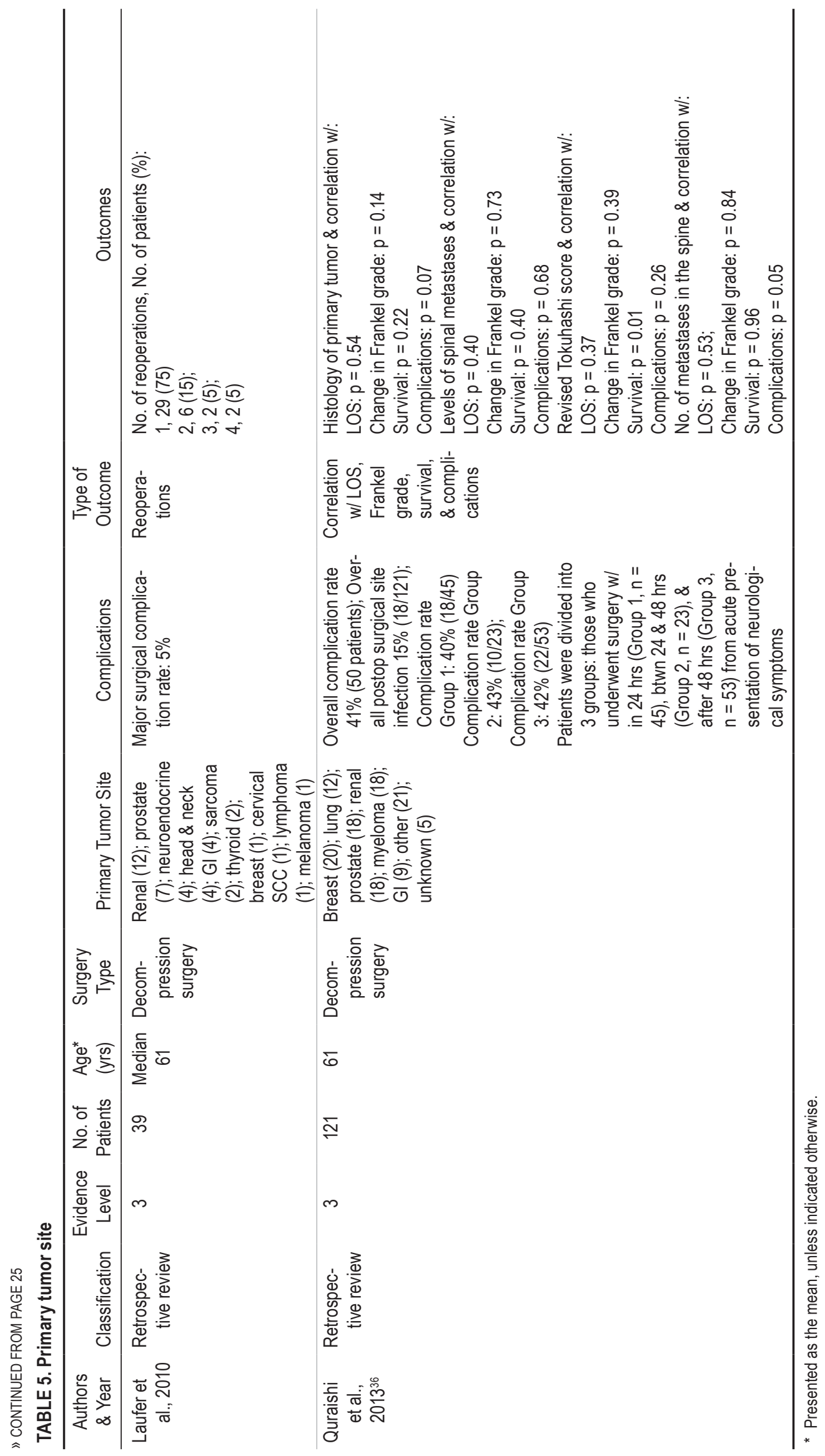




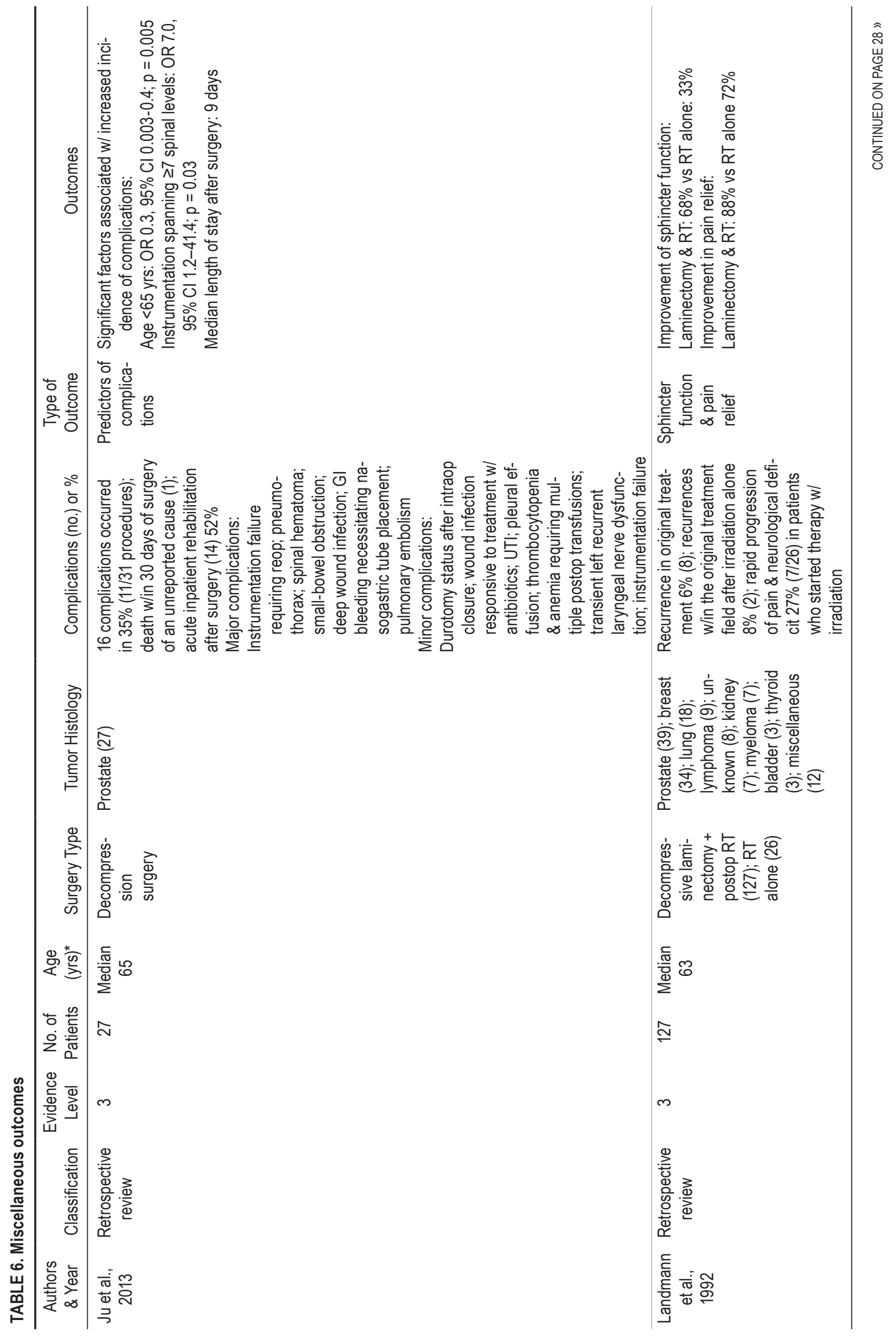




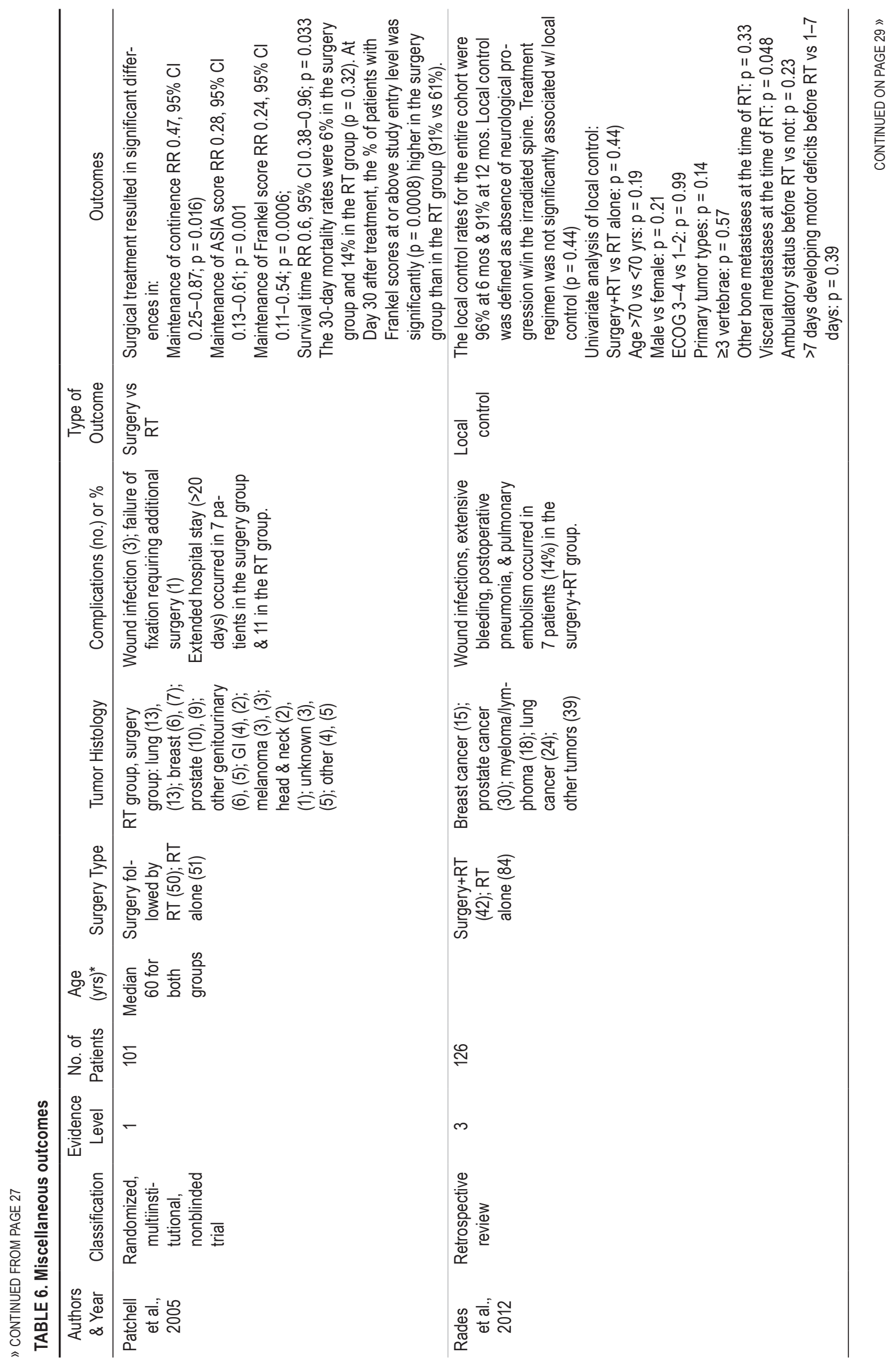




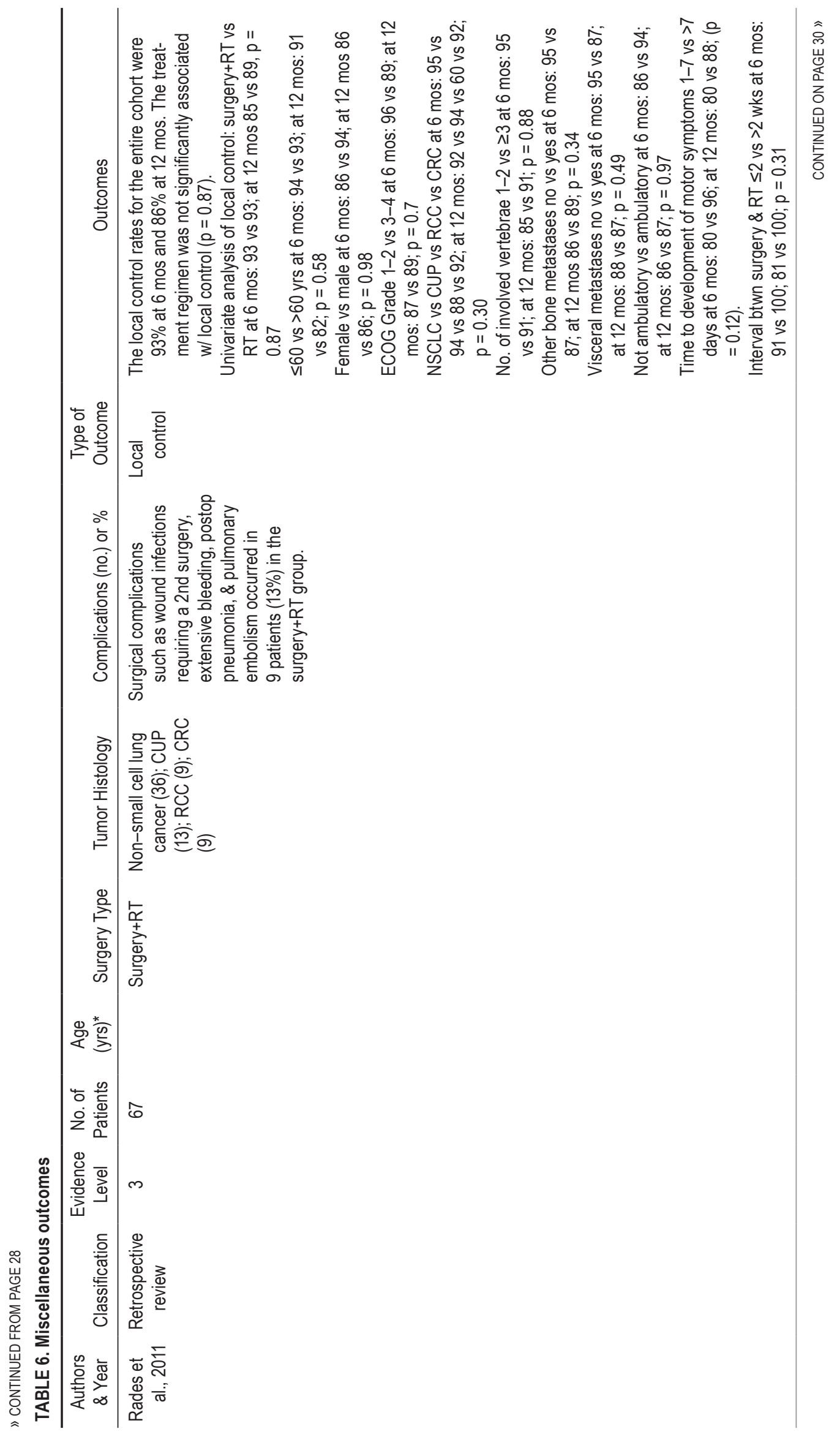




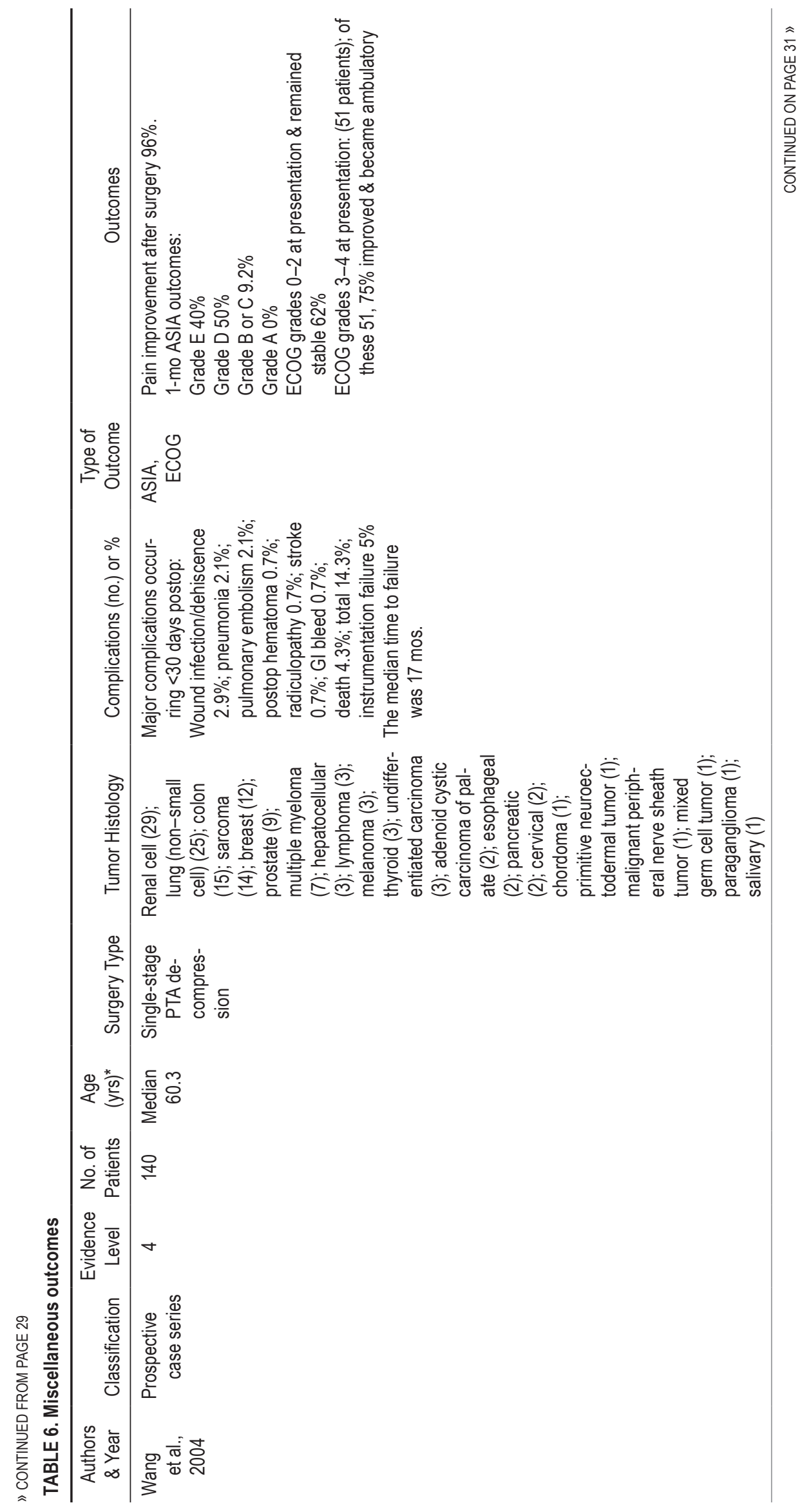




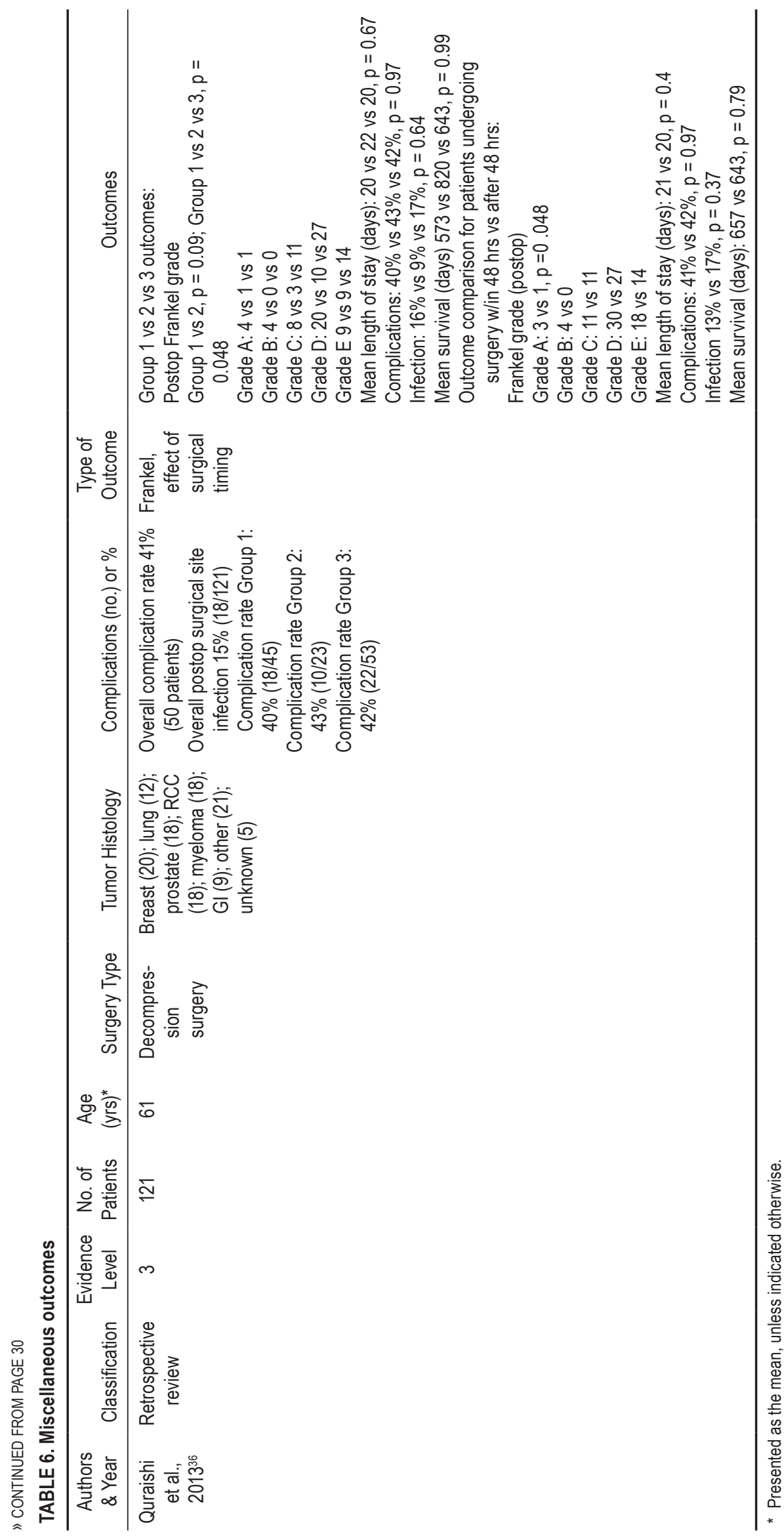


tastases module (EORTC QLQ-BM22) $(\mathrm{p}=0.03)$ relative to patients who underwent laminectomy and stabilization via traditional open surgery. ${ }^{23}$ Similarly Tancioni et al. ${ }^{41}$ reported outcomes in 25 consecutive patients treated with minimally invasive surgery and noted clinical remission of pain in $96 \%$ of patients and improvement of neurological deficit in $88 \%$ of patients.

Abel et al. ${ }^{1}$ retrospectively studied 34 patients who underwent posterior decompression and stabilization for metastatic compression of the thoracic spinal cord and found that there was no significant difference between the mean ASIA motor score at admission and discharge (72.1 vs 73.5 , respectively; $p=0.7$ ). Furthermore, the authors found no evidence that anterior approaches were superior to posterior approaches for MESCC in the thoracic spine.

\section{Neurological Function}

Eight studies reported outcomes on neurological function (Table 4). ${ }^{5,6,12,17,21,34,36,41}$ Seven studies were retrospective and one was a nonrandomized, prospective study. The 7 retrospective studies used different decompression techniques, and the prospective study used a minimally invasive approach. Four studies reported functional status using the following methods: Frankel score, visual analog scale (VAS), Tokuhashi Score, and the KPS. 5,6,21,34 The most prevalent primary tumors reported were lung (7 studies), prostate (6 studies), and breast (6 studies).

Three studies reported improvement in neurological function following decompression surgery. ${ }^{12,17,41}$ Landmann et al. ${ }^{17}$ found that sphincter function recovered in $68 \%$ of patients who underwent decompressive laminectomy and received postoperative radiation therapy compared with only $33 \%$ of patients treated by radiotherapy alone. The authors also reported that pain relief was achieved in $88 \%$ of cases after combined treatment compared with $72 \%$ of patients after radiation only. ${ }^{17}$ Furthermore, Landmann et al. ${ }^{17}$ found that $91 \%$ (127/140) of patients that underwent laminectomy followed by adjuvant radiotherapy had improved postoperative neurological outcomes. In their study, $82 \%$ of paraparetic patients regained ambulatory ability, 68\% showed an improvement in sphincter function, and $88 \%$ achieved pain relief. Conversely, in patients treated with radiation therapy alone, only $64 \%$ of paraparetic patients became ambulatory, while 33\% showed an improvement in sphincter function, and $72 \%$ became pain free.

Quraishi et al..$^{36}$ studied the effect of the timing of surgery on neurological outcome and survival in patients with MESCC. The authors found that surgery should be performed earlier rather than later relative to the onset of compression symptoms, as the Frankel grade improvement was significantly better $(p=0.05)$ in patients that underwent surgery within 48 hours of acute neurological deterioration relative to patients who underwent surgery 48 hours or more following presentation. ${ }^{36}$

In a separate study, Quraishi et al. ${ }^{34}$ were the first to use the Bilsky 6-point scale to group patients according to the degree of preoperative cord compression prior to undergoing decompression with and without stabilization. The authors found that increased preoperative compression grade was associated with greater improvement in postoperative
Frankel scores. ${ }^{34}$ Additionally, there were no significant differences between complication rates or median survival times across patient groups $(\mathrm{p}=0.6){ }^{34}$

\section{Radiation Therapy and Local Control}

Four studies reported the effects of radiation therapy and local disease control for spinal metastases. . $^{13,25,37,38}$ Rades et al. ${ }^{37}$ studied local control rates among patients receiving surgery and radiotherapy versus radiotherapy alone. The authors found that for 67 patients who underwent surgery with radiotherapy, the local control rate was $93 \%$ at 6 months and $86 \%$ at 12 months. ${ }^{37}$ Rades et al. ${ }^{37}$ included a matched-pair analysis and found that patients with MESCC from an unfavorable primary tumor (i.e., radioresistant tumors such as renal cell carcinoma and colorectal cancer) had improved functional outcome following decompressive surgery and stabilization in addition to radiotherapy, but not after laminectomy with radiotherapy. The authors suggested that laminectomy should not be considered a viable treatment option before radiotherapy in patients with MESCC. ${ }^{37}$ Rades et al. ${ }^{37}$ found that the type of treatment was not significantly associated with the rate of local control $(p=0.9)$. In another study, Rades et al $^{38}$ analyzed data from 42 elderly (age $>65$ years) patients with MESCC who underwent surgery and received radiotherapy and found that $96 \%$ of patients had local control at 6 months and $91 \%$ at 12 months. Rades et al..$^{38}$ also found that the type of treatment was not significantly associated with the rate of local control $(\mathrm{p}=0.4)$.

One study found that spinal radiation before surgical decompression can have a negative impact on surgical outcomes for MESCC. Ghogawala et al. ${ }^{13}$ reported that the major wound complication rate for patients who received radiation before surgical decompression and stabilization was $32 \%$, significantly higher than the $12 \%$ seen in patients who had surgery first $(\mathrm{p}<0.05)$.

\section{Complications}

Complications reported among the included studies were varied. However, the most commonly cited complication was wound infection or dehiscence (22 studies), which occurred in $2.5 \%$ to $16 \%$ of patients. ${ }^{1,3-5,12,13,15,21,22,29-}$ 35,37-39,41,43,45 Chaichana et al. ${ }^{3}$ did not find a statistically significant difference in the incidence rate of complications among spinal metastases based on primary tumor site. However, Ju et al. ${ }^{15}$ reported that younger age $(\mathrm{p}<0.01)$ and instrumentation greater than 7 spinal levels $(p=0.03)$ were associated with increased odds of complication in patients with MESCC stemming from prostate cancer. Quraishi et al. ${ }^{36}$ compared complication rates based on timing of surgery and determined that the incidence of complications was similar among those treated with surgery within 24 hours (40\% complication rate), between 24 and 48 hours $(43 \%)$, and over 48 hours $(42 \%)$ following acute presentation of neurological symptoms $(\mathrm{p}=1.0)$.

\section{Primary Tumor Site}

Five studies reported outcomes based on site of primary tumor (Table 5). ${ }^{2,3,11,18,36}$ All 5 studies were retrospective. The most common primary tumor site included renal 
cancer (4 studies), breast cancer (3 studies), prostate cancer (3 studies), gastrointestinal cancer (3 studies), and lung cancer (2 studies).

Laufer et al. ${ }^{18}$ found that 29/39 (75\%) patients who underwent decompression surgery required at least 1 reoperation regardless of tumor histology (Table 6). In contrast, Chaichana et al. ${ }^{3}$ compared long-term surgical outcomes based on primary tumor histology and found that patients with primary prostate cancers had the shortest mean duration of spinal cord compression symptoms prior to surgery $(\mathrm{p}<0.05)$, but they presented with motor deficits more frequently compared with all other histology types $(\mathrm{p}<0.05)$. The authors also found that patients with primary breast cancer histology were more likely to present with cervical MESCC than patients with primary lung cancer histology $(p=0.04)$ and were more likely to present with compression fractures relative to patients with primary prostate cancers $(p=0.04){ }^{3}$

\section{Miscellaneous}

Seven studies reported outcomes not related to the previous topics (Table 6). ${ }^{15,17,32,36-38,45}$ The most common primary tumor sites included prostate cancer (6 studies), lung cancer (6 studies), breast cancer ( 5 studies), and renal cancer ( 3 studies). Five of the studies were retrospective and 2 were prospective.

Laufer et al. ${ }^{18}$ analyzed the functional outcomes and complications associated with reoperation for MESCC and found that reoperation can improve outcomes among patients with high-grade epidural spinal cord compression with persistent metastatic tumors at previously treated spinal levels. Specifically, the authors found that $97 \%$ of patients maintained or had an improvement in functional status by one ECOG grade.

\section{Discussion}

The present study comprehensively reviews the literature on decompression surgery for spinal metastases. Included studies were classified according to the outcomes reported. Specifically, studies were categorized as reporting survival outcomes, ambulation outcomes, surgical technique, neurological function outcomes, primary tumor histology outcomes, and miscellaneous outcomes. Table 1 reported a wide range of predictors of survival, including Motzer score, Tokuhashi score, Frankel grade, KPS, and ECOG performance status. Table 2 reported several predictors of ambulatory status or motor function including Frankel grade, ECOG score, ASIA grade, and KPS. Table 3 reported different surgical techniques for decompression surgery and mostly focused on ASIA grade outcomes. Table 4 reported neurological functional outcomes and mostly reported outcomes using ASIA grade, Frankel grade, and KPS. Table 5 reported outcomes based on primary tumor site and reported a variety of long-term surgical outcomes including survival outcomes, reoperation rates, and correlations of primary tumor site with length of stay, change in Frankel grade, survival, and complications. Lastly, Table 6 reported miscellaneous outcomes including predictors of complications, sphincter function and pain relief, local control rates, stereotactic radiosur- gery dosage, and the effect of surgical timing on Frankel grades. A review of these clinical parameters can improve preoperative risk counseling and help surgeons optimize their choice of surgical technique to decrease the occurrence of postoperative complications and improve patient quality of life.

\section{Predictors of Survival}

Survival was the most commonly reported outcome. Different scoring algorithms have been proposed to improve survival prediction among patients with spinal metastases who undergo decompression surgery. Three studies found that KPS was associated with survival following decompression surgery. ${ }^{7,15,28} \mathrm{Ju}$ et al. ${ }^{15}$ found that a better preoperative KPS (defined as KPS $\geq 80 \%$ ) was the only significant predictor of survival in a multivariable study of patients with prostate cancer metastatic to the spine (HR 6.1 [95\% CI 1.3-28.5], $\mathrm{p}=0.02$ ). Padalkar et al. ${ }^{28}$ also found that increased KPS was significantly associated with greater median survival times in patients treated with decompression with instrumentation for spinal metastases. Crnalic et al. reported that a KPS of $80 \%-100 \%$ was significantly associated with prolonged survival, with a median survival of 5 months.

\section{Predictors of Ambulatory Status/Motor Function}

A prior study found that ambulatory ability is the single most important factor for surgeons when deciding if surgical intervention is an appropriate treatment for patients with metastatic spinal cord compression. ${ }^{22}$ We found that 8 studies reported that preoperative ambulatory or preoperative motor status was a significant predictor of postoperative ambulatory status.,13,16,20,29-31,33 However, we did not find any evidence of a surgical decision-making tool that uses postoperative ambulation as an outcome following decompression surgery for spinal metastases. Future studies are warranted to develop evidence-based decisionmaking tools that use postoperative ambulatory status as an outcome. These decision tools may significantly improve preoperative patient risk counseling and patient selection for decompression surgery for spinal metastases.

\section{Description of Surgical Techniques}

We found 5 studies that identified outcomes following different surgical techniques for decompression surgery among patients with spinal metastases. . $^{12,23,39,45}$ In reviewing the aforementioned studies on surgical technique, the only prospective studies were those by Miscusi et al. ${ }^{23}$ and Wang et al. ${ }^{45}$ Furthermore, no studies reported using matching techniques, such as propensity matching, which help mitigate bias in observational studies. Therefore, despite promising evidence of the benefits of the innovative surgical techniques described above, larger prospective, randomized trials or rigorously designed observational studies are needed to appropriately evaluate the effectiveness of different surgical approaches for decompression surgery among patients with spinal metastases.

\section{Neurological Function}

Two studies found that neurological outcomes may 
improve if decompression surgery is performed within 48 hours of MESCC symptom presentation. Fürstenberg et al. ${ }^{12}$ studied 35 patients who underwent early surgical treatment for MESCC and found that early surgical treatment was associated with improved neurological outcomes as measured by the ASIA grade $(p=0.02)$. Similarly, Quraishi et al. ${ }^{36}$ found that surgery should be performed earlier rather than later among patients with MESCC, as the Frankel grade improvement was significantly greater $(p=0.05)$ among patients who received surgery within 48 hours of presenting with symptoms relative to patients who received surgery after 48 hours. ${ }^{36}$

\section{Conclusions}

This work presents a comprehensive systematic review of outcomes following decompression surgery for metastatic spinal tumors of varied primary tumor sites. The present study highlights significant predictors of survival, ambulation, and functional status following decompression surgery for metastatic spine disease. The results of the data presented herein also identify significant gaps in the literature, which may help spur additional investigation of the optimal surgical management of patients with MESCC.

\section{References}

1. Abel R, Keil M, Schläger E, Akbar M: Posterior decompression and stabilization for metastatic compression of the thoracic spinal cord: is this procedure still state of the art? Spinal Cord 46:595-602, 2008

2. Bakker NA, Coppes MH, Vergeer RA, Kuijlen JM, Groen RJ: Surgery on spinal epidural metastases (SEM) in renal cell carcinoma: a plea for a new paradigm. Spine J 14:20382041, 2014

3. Chaichana KL, Pendleton C, Sciubba DM, Wolinsky JP, Gokaslan ZL: Outcome following decompressive surgery for different histological types of metastatic tumors causing epidural spinal cord compression. Clinical article. J Neurosurg Spine 11:56-63, 2009

4. Chaichana KL, Woodworth GF, Sciubba DM, McGirt MJ, Witham TJ, Bydon A, et al: Predictors of ambulatory function after decompressive surgery for metastatic epidural spinal cord compression. Neurosurgery 62:683-692, 2008

5. Chong S, Shin SH, Yoo H, Lee SH, Kim KJ, Jahng TA, et al: Single-stage posterior decompression and stabilization for metastasis of the thoracic spine: prognostic factors for functional outcome and patients' survival. Spine J 12:1083-1092, 2012

6. Crnalic S, Hildingsson C, Bergh A, Widmark A, Svensson $\mathrm{O}$, Löfvenberg R: Early diagnosis and treatment is crucial for neurological recovery after surgery for metastatic spinal cord compression in prostate cancer. Acta Oncol 52:809-815, 2013

7. Crnalic S, Löfvenberg R, Bergh A, Widmark A, Hildingsson $\mathrm{C}$ : Predicting survival for surgery of metastatic spinal cord compression in prostate cancer: a new score. Spine (Phila Pa 1976) 37:2168-2176, 2012

8. Delank KS, Wendtner C, Eich HT, Eysel P: The treatment of spinal metastases. Dtsch Arztebl Int 108:71-80, 2011

9. Drew M, Dickson RB: Osseous complications of malignancy, in Lokich JJ (ed): Clinical Cancer Medicine: Treatment Tactics. Boston: G. K. Hall, 1980, pp 97-124

10. Dunning EC, Butler JS, Morris S: Complications in the management of metastatic spinal disease. World J Orthop 3:114-121, 2012
11. Enkaoua EA, Doursounian L, Chatellier G, Mabesoone F, Aimard T, Saillant G: Vertebral metastases: a critical appreciation of the preoperative prognostic Tokuhashi score in a series of 71 cases. Spine (Phila Pa 1976) 22:2293-2298, 1997

12. Fürstenberg CH, Wiedenhöfer B, Gerner HJ, Putz C: The effect of early surgical treatment on recovery in patients with metastatic compression of the spinal cord. J Bone Joint Surg Br 91:240-244, 2009

13. Ghogawala Z, Mansfield FL, Borges LF: Spinal radiation before surgical decompression adversely affects outcomes of surgery for symptomatic metastatic spinal cord compression. Spine (Phila Pa 1976) 26:818-824, 2001

14. Hatrick NC, Lucas JD, Timothy AR, Smith MA: The surgical treatment of metastatic disease of the spine. Radiother Oncol 56:335-339, 2000

15. Ju DG, Zadnik PL, Groves ML, Hwang L, Kaloostian PE, Wolinksy JP, et al: Factors associated with improved outcomes following decompressive surgery for prostate cancer metastatic to the spine. Neurosurgery 73:657-666, 2013

16. Kondo T, Hozumi T, Goto T, Seichi A, Nakamura K: Intraoperative radiotherapy combined with posterior decompression and stabilization for non-ambulant paralytic patients due to spinal metastasis. Spine (Phila Pa 1976) 33:1898-1904, 2008

17. Landmann C, Hünig R, Gratzl O: The role of laminectomy in the combined treatment of metastatic spinal cord compression. Int J Radiat Oncol Biol Phys 24:627-631, 1992

18. Laufer I, Hanover A, Lis E, Yamada Y, Bilsky M: Repeat decompression surgery for recurrent spinal metastases. J Neurosurg Spine 13:109-115, 2010

19. Lei M, Liu Y, Tang C, Yang S, Liu S, Zhou S: Prediction of survival prognosis after surgery in patients with symptomatic metastatic spinal cord compression from non-small cell lung cancer. BMC Cancer 15:853, 2015

20. Lei M, Liu Y, Yan L, Tang C, Liu S, Zhou S: Posterior decompression and spine stabilization for metastatic spinal cord compression in the cervical spine. A matched pair analysis. Eur J Surg Oncol 41:1691-1698, 2015

21. Lei M, Liu Y, Yan L, Tang C, Yang S, Liu S: A validated preoperative score predicting survival and functional outcome in lung cancer patients operated with posterior decompression and stabilization for metastatic spinal cord compression. Eur Spine J [epub ahead of print], 2015

22. Majeed H, Kumar S, Bommireddy R, Klezl Z, Calthorpe $\mathrm{D}$ : Accuracy of prognostic scores in decision making and predicting outcomes in metastatic spine disease. Ann R Coll Surg Engl 94:28-33, 2012

23. Miscusi M, Polli FM, Forcato S, Ricciardi L, Frati A, Cimatti $\mathrm{M}$, et al: Comparison of minimally invasive surgery with standard open surgery for vertebral thoracic metastases causing acute myelopathy in patients with short- or mid-term life expectancy: surgical technique and early clinical results. J Neurosurg Spine 22:518-525, 2015

24. Moher D, Liberati A, Tetzlaff J, Altman DG: Preferred reporting items for systematic reviews and meta-analyses: the PRISMA statement. BMJ 339:b2535, 2009

25. Moulding HD, Elder JB, Lis E, Lovelock DM, Zhang Z, Yamada Y, et al: Local disease control after decompressive surgery and adjuvant high-dose single-fraction radiosurgery for spine metastases. J Neurosurg Spine 13:87-93, 2010

26. Moussazadeh N, Laufer I, Yamada Y, Bilsky MH: Separation surgery for spinal metastases: effect of spinal radiosurgery on surgical treatment goals. Cancer Contr 21:168-174, 2014

27. Ortiz Gómez JA: The incidence of vertebral body metastases. Int Orthop 19:309-311, 1995

28. Padalkar P, Tow B: Predictors of survival in surgically treated patients of spinal metastasis. Indian J Orthop 45:307313,2011 
29. Park JH, Jeon SR: Pre- and postoperative lower extremity motor power and ambulatory status of patients with spinal cord compression due to a metastatic spinal tumor. Spine (Phila Pa 1976) 38:E798-E802, 2013

30. Park JH, Rhim SC, Jeon SR: Efficacy of decompression and fixation for metastatic spinal cord compression: analysis of factors prognostic for survival and postoperative ambulation. J Korean Neurosurg Soc 50:434-440, 2011

31. Park SJ, Lee CS, Chung SS: Surgical results of metastatic spinal cord compression (MSCC) from non-small cell lung cancer (NSCLC): analysis of functional outcome, survival time, and complication. Spine J 16:322-328, 2016

32. Patchell RA, Tibbs PA, Regine WF, Payne R, Saris S, Kryscio RJ, et al: Direct decompressive surgical resection in the treatment of spinal cord compression caused by metastatic cancer: a randomised trial. Lancet 366:643-648, 2005

33. Putz C, Gantz S, Bruckner T, Moradi B, Helbig L, Gerner $\mathrm{HJ}$, et al: Preoperative scoring and limits of prognostication: functional outcome after surgical decompression in metastatic spinal cord compression. Oncology 86:177-184, 2014 (Erratum in Oncol 88:260, 2015)

34. Quraishi NA, Arealis G, Salem KM, Purushothamdas S, Edwards KL, Boszczyk BM: The surgical management of metastatic spinal tumors based on an epidural spinal cord compression (ESCC) scale. Spine J 15:1738-1743, 2015

35. Quraishi NA, Manoharan SR, Arealis G, Khurana A, Elsayed S, Edwards KL, et al: Accuracy of the revised Tokuhashi score in predicting survival in patients with metastatic spinal cord compression (MSCC). Eur Spine J 22 (Suppl 1):S21S26, 2013

36. Quraishi NA, Rajagopal TS, Manoharan SR, Elsayed S, Edwards KL, Boszczyk BM: Effect of timing of surgery on neurological outcome and survival in metastatic spinal cord compression. Eur Spine J 22:1383-1388, 2013

37. Rades D, Huttenlocher S, Bajrovic A, Karstens JH, Adamietz IA, Kazic N, et al: Surgery followed by radiotherapy versus radiotherapy alone for metastatic spinal cord compression from unfavorable tumors. Int J Radiat Oncol Biol Phys 81:e861-e868, 2011

38. Rades D, Huttenlocher S, Evers JN, Bajrovic A, Karstens JH, Rudat V, et al: Do elderly patients benefit from surgery in addition to radiotherapy for treatment of metastatic spinal cord compression? Strahlenther Onkol 188:424-430, 2012

39. Schoeggl A, Reddy M, Matula C: Neurological outcome following laminectomy in spinal metastases. Spinal Cord 40:363-366, 2002

40. Spencer BA, Shim JJ, Hershman DL, Zacharia BE, Lim EA, Benson MC, et al: Metastatic epidural spinal cord compression among elderly patients with advanced prostate cancer. Support Care Cancer 22:1549-1555, 2014
41. Tancioni F, Navarria P, Pessina F, Marcheselli S, Rognone E, Mancosu P, et al: Early surgical experience with minimally invasive percutaneous approach for patients with metastatic epidural spinal cord compression (MESCC) to poor prognoses. Ann Surg Oncol 19:294-300, 2012

42. Valesin Filho ES, de Abreu LC, Lima GHV, de Cubero DIG, Ueno FH, Figueiredo GSL, et al: Pain and quality of life in patients undergoing radiotherapy for spinal metastatic disease treatment. Int Arch Med 6:6-16, 2013

43. Vanek P, Bradac O, Trebicky F, Saur K, de Lacy P, Benes V: Influence of the preoperative neurological status on survival after the surgical treatment of symptomatic spinal metastases with spinal cord compression. Spine (Phila Pa 1976) 40:1824-1830, 2015

44. Walsh GL, Gokaslan ZL, McCutcheon IE, Mineo MT, Yasko AW, Swisher SG, et al: Anterior approaches to the thoracic spine in patients with cancer: indications and results. Ann Thorac Surg 64:1611-1618, 1997

45. Wang JC, Boland P, Mitra N, Yamada Y, Lis E, Stubblefield M, et al: Single-stage posterolateral transpedicular approach for resection of epidural metastatic spine tumors involving the vertebral body with circumferential reconstruction: results in 140 patients. Invited submission from the Joint Section Meeting on Disorders of the Spine and Peripheral Nerves, March 2004. J Neurosurg Spine 1:287-298, 2004

\section{Disclosures}

The authors report the following. Dr. Steinmetz: consultant for Biomet Spine, Globus Spine, DePuy Synthes, Stryker, and Intellirod. Dr. Mroz: consultant for Stryker and Ceramtec and direct stock ownership in Pearl Diver.

\section{Author Contributions}

Conception and design: Mroz, Tanenbaum, Alentado, Steinmetz, Benzel. Acquisition of data: Bakar, Tanenbaum, Phan, Alentado. Analysis and interpretation of data: Bakar, Tanenbaum, Alentado. Drafting the article: Bakar. Critically revising the article: Bakar, Tanenbaum, Alentado, Steinmetz, Benzel. Reviewed submitted version of manuscript: all authors. Approved the final version of the manuscript on behalf of all authors: Mroz. Administrative/ technical/material support: Mroz, Steinmetz, Benzel. Study supervision: Mroz, Steinmetz, Benzel.

\section{Correspondence}

Thomas E. Mroz, Departments of Orthopaedic and Neurological Surgery, Center for Spine Health, The Cleveland Clinic, 9500 Euclid Ave., S-40, Cleveland, OH 44195. email: mrozt@ccf.org. 